\title{
SMOS satellite L-band radiometer: A new capability for ocean surface remote sensing in hurricanes
}

\author{
Nicolas Reul, ${ }^{1}$ Joseph Tenerelli, ${ }^{2}$ Bertrand Chapron, ${ }^{1}$ Doug Vandemark, ${ }^{3}$ Yves Quilfen, ${ }^{1}$ \\ and Yann Kerr ${ }^{4}$ \\ Received 26 July 2011; revised 9 November 2011; accepted 28 November 2011; published 2 February 2012.
}

[1] The Soil Moisture and Ocean Salinity (SMOS) mission currently provides multiangular L-band $(1.4 \mathrm{GHz})$ brightness temperature images of the Earth. Because upwelling radiation at $1.4 \mathrm{GHz}$ is significantly less affected by rain and atmospheric effects than at higher microwave frequencies, these new SMOS measurements offer unique opportunities to complement existing ocean satellite high wind observations that are often contaminated by heavy rain and clouds. To illustrate this new capability, we present SMOS data over hurricane Igor, a tropical storm that developed to a Saffir-Simpson category 4 hurricane from 11 to 19 September 2010. Thanks to its large spatial swath and frequent revisit time, SMOS observations intercepted the hurricane 9 times during this period. Without correcting for rain effects, L-band wind-induced ocean surface brightness temperatures $\left(T_{B}\right)$ were co-located and compared to $\mathrm{H}^{*}$ Wind analysis. We find the L-band ocean emissivity dependence with wind speed appears less sensitive to roughness and foam changes than at the higher C-band microwave frequencies. The first Stokes parameter on a $\sim 50 \mathrm{~km}$ spatial scale nevertheless increases quasi-linearly with increasing surface wind speed at a rate of $0.3 \mathrm{~K} / \mathrm{m} \mathrm{s}^{-1}$ and $0.7 \mathrm{~K} / \mathrm{m} \mathrm{s}^{-1}$ below and above the hurricane-force wind speed threshold $\left(\sim 32 \mathrm{~m} \mathrm{~s}^{-1}\right)$, respectively. Surface wind speeds estimated from SMOS brightness temperature images agree well with the observed and modeled surface wind speed features. In particular, the evolution of the maximum surface wind speed and the radii of 34, 50 and 64 knots surface wind speeds are consistent with GFDL hurricane model solutions and $\mathrm{H}^{*}$ Wind analyses. The SMOS sensor is thus closer to a true all-weather satellite ocean wind sensor with the capability to provide quantitative and complementary surface wind information of interest for operational Hurricane intensity forecasts.

Citation: Reul, N., J. Tenerelli, B. Chapron, D. Vandemark, Y. Quilfen, and Y. Kerr (2012), SMOS satellite L-band radiometer: A new capability for ocean surface remote sensing in hurricanes, J. Geophys. Res., 117, C02006, doi:10.1029/2011JC007474.

\section{Introduction}

[2] Energy exchange at the air-sea interface is one of the three major physical processes governing hurricane intensity change; the others are environmental interactions with surrounding large-scale features in the atmosphere, and internal dynamics such as eyewall replacement cycles and cloud microphysics. The air-sea exchange of heat, moisture, and momentum determines how hurricanes gain their strength and intensity from the ocean. In this context, measurements of the hurricane surface wind field, and in particular the estimation of wind maxima, have long been a requirement of

\footnotetext{
${ }^{1}$ Laboratoire d'Océanographie Spatiale, Institut Français de Recherche et d'Exploitation de la Mer, Plouzané, France.

${ }^{2}$ Radar Division, Collect Localisation Satellite, Plouzané, France.

${ }^{3}$ Institute for the Study of Earth, Oceans and Space, University of New Hampshire, Durham, New Hampshire, USA.

${ }^{4}$ Centre d'Etude Spatial de la Biosphère, Toulouse, France.

Copyright 2012 by the American Geophysical Union. 0148-0227/12/2011JC007474
}

hurricane prediction centers (e.g., NOAA Tropical Prediction Center/National Hurricane Center).

[3] Owing to satellite-based observations, extreme weather events such as Tropical Cyclones (TC) or midlatitude cyclones and polar lows can be more commonly reported, directly analyzed [e.g., Quilfen et al., 2010, 2011] or indirectly characterized [Ardhuin et al., 2009; Collard et al., 2009; Delpey et al., 2010]. These measurements are critical for short-term forecasting, but also offer the means to better examine the role of extreme conditions for the state of ocean at local and global scales, and storm effects on ocean circulation and ocean heat transport. Energy input in the vicinity of storm tracks is indeed thought to represent the main kinetic energy source necessary to maintain deep ocean stratification and to strengthen ocean stirring processes. As demonstrated using radiometers onboard the Defense Meteorological Satellite Program (DMSP) satellite series, WindSat, TRMM, AMSR, as well as by scatterometers onboard the ERS, ADEOS, QuikScat and METOP satellites, unprecedented synoptic observations of surface wind and atmospheric water content 


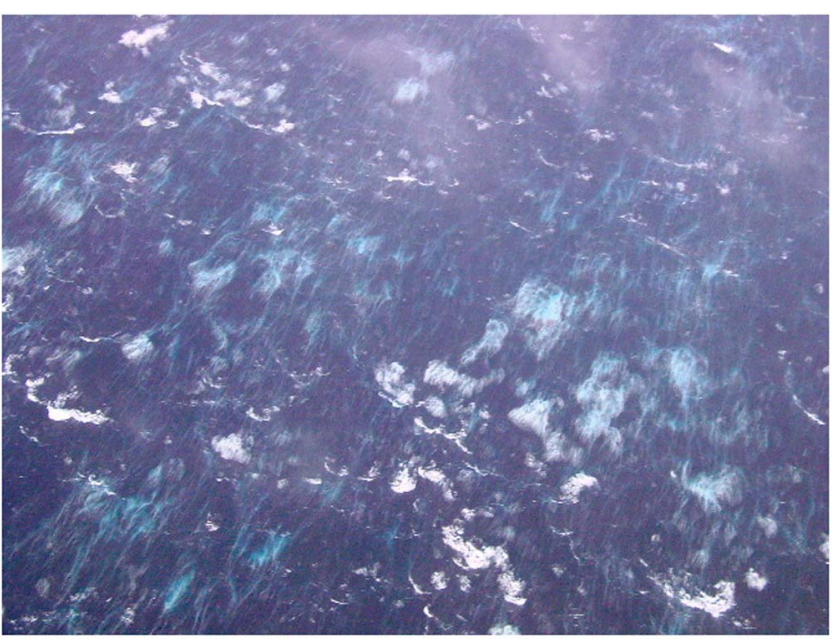

Figure 1. Photograph of the sea surface during a hurricane (Beaufort Force 12) taken from a NOAA "Hurricane Hunter" aircraft [Black et al., 1986].

are now possible and are revealing spatial storm structure with impressive detail. Nevertheless, satellite estimates do not necessarily provide direct measurements of geophysical parameters and can suffer from strong limitations linked to the sensor characteristics. But the combined use of sensors can help to build improved methods to retrieve geophysical information [Knaff et al., 2011].

[4] Considering microwave radiometer sensing of extreme weather events over the oceans, it has long been known and extensively being studied that whitecaps will markedly enhance the microwave emissivity of the portion of the sea surface they cover, making that portion of the sea surface approximate a microwave blackbody with an emissivity of close to unity [see, e.g., Nordberg et al., 1971; Stogryn, 1972; Rosenkranz and Staelin, 1972; Ross and Cardone, 1974; Webster et al., 1976; Smith, 1988; Swift, 1990; Reul and Chapron, 2003; Camps et al., 2005; Padmanabhan et al., 2006; Sharkov, 2006; Raizer, 2007, Anguelova, 2008; Meissner and Wentz, 2009; Yueh et al., 2010]. The increase in sea surface emissivity that occurs even though a very small portion of the sea surface within the "footprint" of a microwave radiometer is covered by whitecaps, is associated with an increase in the microwave brightness temperature as recorded by the radiometer.

[5] For boundary layer wind speeds in excess of $33 \mathrm{~m} \mathrm{~s}^{-1}$ or about 64 knots, which is force 11 to force 12 on the Beaufort Scale [Allen, 1983], sea surface conditions are described as follows: Force 11: "Violent storm. The sea is completely covered with long white patches of foam lying along the direction of the wind. Everywhere the edges of the wave crests are blown into froth. Visibility affected."; Force 12: "Hurricane. The air is filled with foam and spray. Sea completely white with driving spray-visibility very seriously affected." Figure 1 is a photograph taken in Force 11 conditions from a NOAA "Hurricane Hunter" aircraft. As the wind speed increases above hurricane force, the entire surface takes on a whitish cast: $50-55 \%$ of the surface is white. For wind speeds $>45 \mathrm{~m} \mathrm{~s}^{-1}$, the whitish cast covers $100 \%$ of the surface and visually obscures almost all of the surface features [Black et al., 1986]. These changes in foam coverage and physical properties at the sea surface as the wind speed reaches gale force are associated with a strong enhancement of the microwave brightness temperature emitted by the ocean surface. This information can be used as a means of remotely measuring surface wind speeds in hurricanes from airborne, or spaceborne, microwave radiometers. The Step Frequency Microwave Radiometer (SFMR) operating at C-band (4-8 GHz), which is NOAA's primary airborne sensor for measuring tropical cyclone surface wind speeds [Uhlhorn et al., 2007], is based on this principle.

[6] Until very recently, orbiting microwave radiometers (e.g., SSM/I, SSMIS, TMI, TRMM, AMSR, AMSU, CMIS, AMSR-E, and WindSAT) all operated at frequencies higher or equal to C-band. These passive satellite instruments are used to infer cloud liquid water, water vapor, wind speed, rain rate, and, sea surface temperature (SST). At these microwave frequencies, atmospheric absorption, emission and scattering associated with high cloud liquid water content and precipitation prevalent in cyclones can have a large impact on brightness temperatures.

[7] Consequently, it is difficult to infer directly ocean surface wind and whitecap properties at the surface beneath tropical cyclones at these frequencies. The measurement of ocean surface wind speeds under rain has been a long standing problem for passive satellite microwave radiometers. Algorithms have been developed that are able to measure ocean surface wind speeds with an accuracy of at least $1 \mathrm{~m} \mathrm{~s}^{-1}$, as long as the scenes are free of rain [Bettenhausen et al., 2006]. Unfortunately, these algorithms break down completely as soon as even only light rain is present. For accurate radiometer retrievals of wind speeds in rain [Yueh, 2008; Meissner and Wentz, 2009; El-Nimri et al., 2010], it is essential to use brightness temperature signals at different frequencies, whose spectral signature make it possible to find channel combinations that are sufficiently sensitive to wind speed, and only weakly sensitive to rain. Such a technique has been employed successfully for many years for wind speed retrieval with the SFMR, which operates at six closely spaced C-band frequencies from $\sim 4$ to $7 \mathrm{GHz}$. This becomes a much more difficult task when considering orbiting radiometers such as AMSR-E, or WindSat, which probe the earth at several frequencies but in clearly separate bands (e.g., C-band, X-band, Ka-band), with each channel having very distinct geophysical dependencies (e.g., C-band channel being significantly less sensitive to atmosphere, roughness and rain than $\mathrm{X}$ - or Ka-bands, but more sensitive to SST, etc.).

[8] In addition, oceanic whitecaps mark areas with actively producing sea spray droplets via bubble bursting (film and jet droplets), and via the wind tearing off wave crests (spume droplets). Sea spray yields additional radiobrightness [Raizer, 2007] beyond that generated by ocean surface itself. Macroscopic radiative transfer model simulations reveal that when sea spray droplets are located over any foam surface, negative radio-brightness contrasts can appear for radiometer observations at electromagnetic wavelength within the range of $=0.3(\sim 100 \mathrm{GHz})-8 \mathrm{~cm}$ ( $\sim 4 \mathrm{GHz}$ ), with an intensity depending on the incidence angle and polarization. In gale force wind conditions, a thick layer of spray is filling the air above a 'boiling' wavy 
air-sea interface. The so-called "cooling effect" induced by the spray-layer itself on the ocean emitted microwave energy is a result of the scattering of microwave radiation on sea spray droplets and can lead to error when trying to estimate surface winds from radiometer measurements.

[9] While clear progress has been made in the understanding of the ocean scene radio-brightness contrasts dependencies on sea surface foam, rain and spray droplets properties and distributions, the co-existence of these three phenomena at and above the sea surface in extreme wind conditions makes it a difficult task to individually retrieve either surface winds, rain rates, or whitecap properties from spaceborne radiometer microwave observations acquired over hurricanes.

[10] SMOS (Soil Moisture and Ocean Salinity) is the European Space Agency's water mission [Kerr et al. 2010; Mecklenburg et al. 2009], an Earth Explorer Opportunity Mission belonging to its Living Planet Program. It aims to provide global and regular observations of soil moisture and sea surface salinity, which are crucial variables to understand and predict the evolution of the water cycle on our planet. SMOS was launched in November 2009 and the technical approach developed to achieve adequate radiometric accuracy, as well as spatial and temporal resolution compromising between land and ocean science requirements, is polarimetric interferometric radiometry [Ruf et al. 1988; Font et al. 2010]. The SMOS synthetic antenna consists of 69 radiometer elements operating at L-band (frequency $\sim 1.4 \mathrm{GHz}$ ) and distributed along three equally spaced arms, resulting in a planar Y-shaped structure. As compared to real aperture radiometers, in which brightness temperature $\left(T_{B}\right)$ maps are obtained by a mechanical scan of a large antenna, in aperture synthesis radiometers, a $T_{B}$ image is formed through Fourier synthesis from the cross correlations between simultaneous signals obtained from pairs of antenna elements. Multiangular images of the brightness temperature of the earth at such low microwave frequency are now obtained over a large swath width $(\sim 1200 \mathrm{~km})$, with a spatial resolution varying within the swath from $\sim 30 \mathrm{~km}$ to about $80 \mathrm{~km}$, and with a revisit time of less than 3 days.

[11] Our current physical understanding of the evolution of ocean surface emissivity at L-band as the wind speed reaches gale force and its peculiarities with respect higher microwave frequencies is first reviewed in this paper. As shown, L-band ocean emissivity signals are significantly less sensitive to sea surface state changes at high winds than at the higher C-band microwave frequencies. Nevertheless, upwelling radiation at $1.4 \mathrm{GHz}$ is also significantly less affected by rain, spray and atmospheric effects than at higher microwave frequencies. Therefore, the changes in L-band emissivity observed over the oceans in extreme wind conditions are likely dominated by the varying impact of sea foam generated by breaking waves, which mainly depends on surface wind strength and sea state development. As high wind observations are very often contaminated by heavy rain and clouds, SMOS measurements present a unique opportunity to study the meso-scale evolution of surface winds and whitecap statistical properties under hurricanes and severe storms, and to complement existing active and passive observation systems.
[12] To illustrate this new capability, we analyze in this paper SMOS data in the North Atlantic during the evolution of hurricane Igor in September 2010, which was an enormous, long-lived category 4 hurricane, causing widespread damage in Newfoundland, Canada. Igor developed from a Tropical Storm during the very early morning hours of September 8 , rapidly strengthened into a category 4 hurricane the afternoon of September $12(215 \mathrm{~km} / \mathrm{h})$, nearly reaching category 5 intensity early on September 15 with $250 \mathrm{~km} / \mathrm{h}$ winds, then progressively weakened to a category 1 hurricane before its greatest impact in Bermuda on September 19, then maintained its strength as it moved northward slowly evolving into an extra-tropical storm.

[13] The data sets and processing approach used for the analysis of SMOS data acquired in Igor extreme wind conditions are described in a dedicated section of the paper. The spatial distributions of SMOS brightness temperature and of coincident modeled and observed surface wind speed fields are then presented for nine satellite overpasses of hurricane Igor during the period from 11 to 19 September. Co-localized SMOS data with analyzed wind products are available for four out of the nine satellite overpasses of the hurricane and used to derive an average empirical relationship between ocean surface excess brightness temperature at L-band and surface wind speed. Based on this empirical rule, surface wind speed spatial distributions are then retrieved from SMOS brightness data for all satellite overpasses of Igor.

[14] The temporal evolution and the spatial structure of the SMOS retrieved surface wind speed are then compared with hurricane model forecasts and with the observed surface wind speed products. In particular, we analyze the capability of SMOS instrument to provide estimates of the maximum wind speed and its radius, as well as of the radii of 34,50 and 64 knots winds. Results and perspective are discussed in a last section.

\section{A Review on L-Band Radiometer Sensing of Ocean Surface at High Winds}

[15] Our current understanding of the ocean emitted radiation at L-band in high wind conditions is mainly based on semi-empirical developments, recent laboratory and airborne campaigns, and on the SMOS data recently analyzed in the context of ocean salinity remote sensing. We first review present knowledge of the wind-excess emissivity at L-band in high wind conditions. We then discuss potential atmospheric, rain and spray-induced contributions.

\subsection{The Wind-Excess Emissivity of the Ocean at L-Band and High Winds}

[16] As discussed by Reul and Chapron [2003], the contribution of foam formations to sea surface brightness temperature can be modeled as function of the $10 \mathrm{~m}$ height wind speed $U_{10}$ by

$$
T_{B f}\left(\theta, p, f, U_{10}\right)=\int_{0}^{\infty} F\left(U_{10}, \bar{\delta}\right) \cdot T_{s} \cdot e_{B f}(\theta, p, f, \bar{\delta}) d \bar{\delta}
$$

where $f, p$ and $\theta$ are the receiving electromagnetic frequency, polarization and incidence angle of the measuring device respectively, $F\left(U_{10}, \bar{\delta}\right)$ is the conditional fraction of sea 
surface covered by foam with average thickness $\bar{\delta}$ at the given wind speed $U_{10}, T_{s}$, is the physical temperature of foam, usually assumed to be the same as the bulk sea surface temperature, and $e_{B f}(\theta, p, f, \bar{\delta})$ is the emissivity of a typical sea foam-layer with thickness $\bar{\delta}$. Based on this formalism, a dedicated radiative transfer model of the effect of foam on the L-band ocean emission has been developed prior to SMOS launch [Reul and Chapron, 2002; Camps et al., 2005; Zine et al., 2008]. The complete foam emissivity model was further combined with an emissivity model based on the small-slope approximation theory [Johnson and Zhang, 1999] to account for the contribution of the foamfree rough surface on the L-band emission induced by wind speed changes. Integrating over all breaking wave scales, the model of equation (1) predicts that foam layers will only emit L-band radiation if they are thicker than about $10 \mathrm{~cm}$ and that in general conditions, such layers will start to appear at the sea surface only for wind speed in excess of about 12 $13 \mathrm{~m} / \mathrm{s}$. Considering the recent analysis of SMOS observations [e.g., see Tenerelli and Reul, 2010; Boutin et al., 2011], the data show that the foam actually starts to impact the emissivity approximately at the predicted wind speed threshold. However, they revealed that the combined foam and wave-induced emissivity model clearly overestimates the observed rate of growth of the L-band emissivity as the wind speed increases above $12-15 \mathrm{~m} \mathrm{~s}^{-1}$, probably indicating weaknesses in the modeling of the statistical distribution of foam properties $F\left(U_{10}, \bar{\delta}\right)$. These results were found when considering global data to characterize the wind-excess emissivity and using the European Centre for Medium-Range Weather Forecasts (ECMWF) wind speed products up to about $20 \mathrm{~m} \mathrm{~s}^{-1}$. Analysis of the SMOS data for higher surface wind speeds, as can be encountered in hurricanes, cannot be based solely upon ECMWF products because of their known limitations in these severe weather conditions [European Centre for Medium-Range Weather Forecasts, 2004]. A more detailed analysis of SMOS data and the associated validation of the developed forward models at high winds is therefore required.

[17] Yueh et al. [2010] recently conducted L-band microwave brightness temperature measurements of sea surfaces at high winds from an aircraft using the Passive/Active L-band Sensor (PALS). They flew the PALS instrument across a storm in the North Atlantic, with encountered surface wind speeds reaching about $28 \mathrm{~m} \mathrm{~s}^{-1}$ as estimated from concurrent active Ku-band scatterometer acquisitions. These authors found that the passive brightness temperatures at L-band and at $45^{\circ}$ incidence angle show a quasi linear change with surface wind speed, with a sensitivity of about $0.26 \mathrm{~K} / \mathrm{m} \mathrm{s}^{-1}$ in vertical polarization $\left(\mathrm{T}_{\mathrm{V}}\right)$ and about $0.33 \mathrm{~K} / \mathrm{m} \mathrm{s}^{-1}$, in horizontal polarization $\left(\mathrm{T}_{\mathrm{H}}\right)$. In addition, these authors examined the wind speed response of $T_{B}$ over a wide range of earth incidence and azimuth angles, analyzing data acquired during aircraft roll and circle maneuvers. For earth incidence angles ranging from $20^{\circ}$ to $50^{\circ}$, they found that the linear sensitivity of the first Stokes parameter $\left(\mathrm{T}_{\mathrm{H}}+\mathrm{T}_{\mathrm{V}}\right) / 2$ to wind speed is quasi-independent of the earth incidence angle, with a mean value of $0.294 \mathrm{~K} / \mathrm{m} \mathrm{s}^{-1}$ and a standard deviation of $\sim 0.012 \mathrm{~K} / \mathrm{m} \mathrm{s}^{-1}$ over the whole incidence angle range [see Yueh et al., 2010, Table 7]. They also found that at an incidence angle of $45^{\circ}, \mathrm{T}_{\mathrm{H}}$ and $\mathrm{T}_{\mathrm{V}}$ showed $1 \mathrm{~K}$ and $1.5 \mathrm{~K}$ peak to peak cosine dependence with respect to wind direction at 14 and $24 \mathrm{~m} / \mathrm{s}$, respectively. Note that $T_{H}$ and $T_{V}$ were found to vary almost in quadrature with the wind direction. When considering the first Stokes parameter $\left(\mathrm{T}_{\mathrm{H}}+\mathrm{T}_{\mathrm{V}}\right) / 2$, as will be done in the remaining of this paper, the reported wind direction impact at $24 \mathrm{~m} / \mathrm{s}$ thus translates into a $0.3 \mathrm{~K}$ peak to peak amplitude signal. According to the wind speed sensitivity found from the PALS data, the wind direction impact on the L-band emissivity at $24 \mathrm{~m} \mathrm{~s}^{-1}$ is therefore approximately equivalent to a $1 \mathrm{~m} \mathrm{~s}^{-1}$ wind speed change.

[18] Assuming the PALS reported linearity in the $T_{B}$ dependence with wind speed is still valid at surface wind speeds higher than $30 \mathrm{~m} \mathrm{~s}^{-1}$, a wind speed increase from 0 to $50 \mathrm{~m} \mathrm{~s}^{-1}$ would therefore translate into an increase in the L-band brightness temperature $\Delta \mathrm{I}=\left(\mathrm{T}_{\mathrm{H}}+\mathrm{T}_{\mathrm{V}}\right) / 2$ on the order of $15 \mathrm{~K}$ with respect a perfectly smooth ocean surface. Such large wind induced radio-brightness contrast will likely be encountered at the ocean surface near hurricanes. It is significant with respect the other contributing sources over the oceans and shall be therefore well detected by SMOS.

[19] Nevertheless, the wind and wave-induced excess emissivity at C-band is about three times more sensitive to changes in sea surface roughness and foam than at L-band in high wind conditions. Based on the relationship between 10-m wind speed measurements from GPS dropwindsondes and SFMR nadir looking radiometer data in hurricanes, Uhlhorn and Black [2003] found a quasi-linear evolution of the brightness temperature with surface wind speed at C-band for winds above $\sim 30 \mathrm{~m} \mathrm{~s}^{-1}$, with a sensitivity on the order of $1 \mathrm{~K} / \mathrm{m} \mathrm{s}^{-1}$.

[20] From an analysis of WindSat C-band $(6.8 \mathrm{GHz})$ data in hurricanes, Quilfen et al. [2007] and Ruf et al. [2008] found a similar sensitivity to wind speed at an incidence angle between $49^{\circ}$ and $55^{\circ}$.

[21] These differences between C-band and L-band excess ocean surface emissivity variation with surface wind speed are summarized in Figure 2a, where we show the L-band PALS, as well as the C-band SFMR and WindSat Geophysical Model Functions (GMF) for the wind excess emissivity. In addition, the results predicted by the L-band forward emissivity model developed to process SMOS data prior launch [Reul and Chapron, 2002; Zine et al., 2008] are also given.

[22] As illustrated, a wind speed increase of $50 \mathrm{~m} \mathrm{~s}^{-1}$ would approximately translate into a $\Delta \mathrm{T}_{\mathrm{B}}$ change at $\mathrm{C}$-band of $\sim 47 \mathrm{~K}$ at $55^{\circ}$ for a sea surface temperature of $300 \mathrm{~K}$, an impact which is about three times more than the one predicted by the PALS L-band GMF at an incidence of $45^{\circ}$. As already found from SMOS and ECMWF data [Tenerelli and Reul, 2010], for wind speed in excess of $\sim 15 \mathrm{~m} \mathrm{~s}^{-1}$, the SMOS model we developed is shown to strongly overestimate the growth of L-band emissivity at Hurricane-force wind speed in comparison to the predictions from the PALS GMF.

\subsection{Contributions of Atmosphere, Rain and Spray at L-Band}

[23] According to PALS, WindSat and SFMR data, L-band ocean emissivity signals are therefore significantly less sensitive to sea surface state changes than at the higher C-band microwave frequencies in high winds. Nevertheless, the contribution of rain, atmospheric effects (oxygen, clouds 
(a)

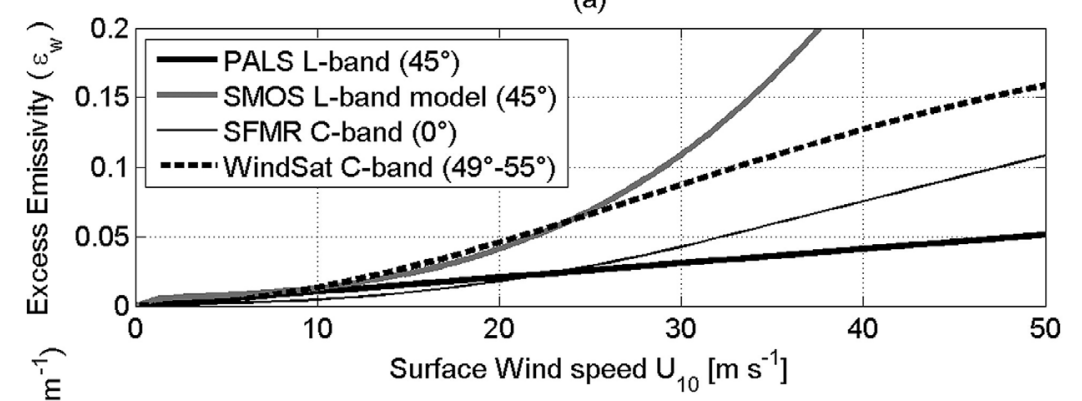

(b)

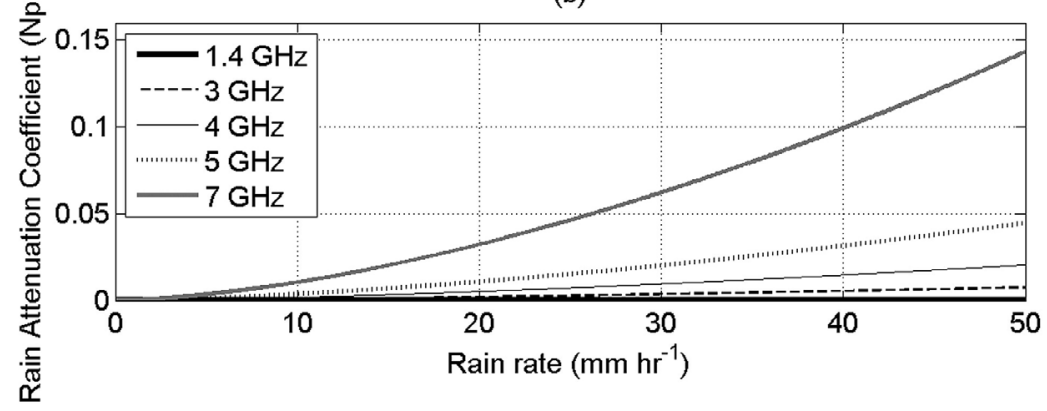

Figure 2. (a) Geophysical Model Functions (GMF) of the wind-induced excess total power emissivity $\varepsilon_{\mathrm{W}}=\left(\varepsilon_{\mathrm{H}}+\varepsilon_{\mathrm{V}}\right) / 2$ as a function of $10 \mathrm{~m}$ height surface wind speed for L-band and C-band frequencies. Thick black curve: L-band GMF estimated from an aircraft campaign using the Passive/Active L-band (PALS) sensor at $45^{\circ}$ incidence [Yueh et al., 2010]; thick gray curve: L-band GMF from the SMOS pre-launch emissivity model [Reul and Chapron, 2003; Zine et al., 2008] at $45^{\circ}$ incidence, thin-black curve: C-band GMF of the SFMR [Uhlhorn et al., 2007] at nadir and thick dash-dotted curve: C-band GMF for WindSat at an incidence of $49^{\circ}-55^{\circ}$ [Ruf et al., 2008]. (b) Rainfall attenuation coefficient (Nepper $\mathrm{km}^{-1}$ ) plotted as a function of rain rate $\left(\mathrm{mm} \mathrm{h}^{-1}\right)$ for different electromagnetic frequencies ranging from L-band $(1.4 \mathrm{GHz}$ ) to $\mathrm{C}$-band (up to $7 \mathrm{GHz}$ ).

liquid water, water vapor) and sea spray to the earth emitted brightness temperature are also significantly smaller at the SMOS frequency. A detailed analysis of various atmospheric error sources that influence the microwave remote sensing of the ocean surface salinity at $1.4 \mathrm{GHz}$ has been carried out by Yueh et al. [2001] and Skou and HoffmanBang [2005]. According to these authors, the dominant atmospheric contribution at L-band is from absorption and emission due to oxygen. The increase in $T_{B}$ due to oxygen in the atmosphere increases with increasing surface pressure and decreasing surface air temperature. An increase of $10 \mathrm{mbar}$ surface pressure increases $T_{B}$ at an incidence of $40^{\circ}$ by about $0.05 \mathrm{~K}$. In low pressure, warm air temperature systems such as tropical cyclones, a very large error of $100 \mathrm{mbar}$ on the surface pressure would therefore yield an error on the oxygen contribution to L-band $\mathrm{T}_{\mathrm{B}}$ on the order of $0.5 \mathrm{~K}$. It was also found that the water vapor and clouds have a very small contribution at $1.4 \mathrm{GHz}$, in general well below $0.1 \mathrm{~K}$.

[24] The effect of rain on the signal at satellite altitude is estimated to be generally small at $1.4 \mathrm{GHz}$ but a thick and heavy rainwater layer may have the potential to alter the brightness temperature significantly. Because of the small ratio of raindrop size to the SMOS electromagnetic wavelength $(\sim 21 \mathrm{~cm})$, scattering by rain is almost negligible at L-band, even at the high rain rates experienced in hurricanes. Thus, rain impact at $1.4 \mathrm{GHz}$ can be approximated entirely by absorption and emission and the Rayleigh scattering approximation is valid for specifying the absorption coefficient for liquid water. According to the Uhlhorn and Black [2003, 2007] model for the absorption coefficient by rain at low microwave frequencies and shown in Figure $2 b$, the latter is generally two orders of magnitude smaller at L-band $(1.4 \mathrm{GHz})$ than at C-band $(5-7 \mathrm{GHz})$. Same results were found by Schulz [2002] and Wentz [2005]. Due to the fact that the absorption coefficient is extremely small at $1.4 \mathrm{GHz}$ (as compared to unity), Wentz [2005] argued that an excellent approximation for the increase in $T_{B}$ due to the presence of cloud liquid water and rain is the following:

$$
\Delta T_{B, \text { liq }}=2(1-E) \bar{T}_{\text {liq }} \bar{a}_{\text {ray }} L \sec \theta
$$

where $\mathrm{E}$ is the sea surface emissivity, $\bar{T}_{\text {liq }}$ is the averaged temperature of the rain cloud, $\bar{a}_{r a y}$ is the Rayleigh coefficient at temperature $\bar{T}_{l i q}$, and $L$ is the total content of liquid water in the field of view. Thus, the increase in $\mathrm{T}_{\mathrm{B}}$ due to the presence of clouds and rain at L-band is simply proportional to the total content of liquid water in the field of view. At $45^{\circ}$ incidence angle, simulations performed by Wentz [2005] assuming a tropical rain layer thickness of $3 \mathrm{~km}$ predict an increase in the first stokes parameter due to rain of $\sim 0.2 \mathrm{~K}$ and $\sim 0.35 \mathrm{~K}$ at a rain rate of $10 \mathrm{~mm} \mathrm{~h}^{-1}$ and $30 \mathrm{~mm} \mathrm{~h}^{-1}$, respectively. Skou and Hoffman-Bang [2005] also estimated the increase in $\mathrm{T}_{\mathrm{B}}$ due to rain emission at $1.4 \mathrm{GHz}$ and generally found a similar amplitude for the rain impact at L-band than the Wentz [2005] estimates. In heavy rain with 
rain rates of $60 \mathrm{~mm} \mathrm{~h}^{-1}$ over a rain column layer of $2 \mathrm{~km}$ height, they found that $\Delta T_{B, l i q} \approx 1 \mathrm{~K}$. Based upon the sensitivity of $\left(\mathrm{T}_{\mathrm{h}}+\mathrm{T}_{\mathrm{v}}\right) / 2$ obtained from PALS $(\sim 0.3 \mathrm{~K} / \mathrm{m} / \mathrm{s})$, the results from the Wentz [2005] and Skou and HoffmanBang [2005] studies indicate that the precipitation emission for rain rates in between $10 \mathrm{~mm} \mathrm{~h}^{-1}$ and $60 \mathrm{~mm} \mathrm{~h}^{-1}$ may lead to retrieved wind speed biases between 0.5 and $\sim 3 \mathrm{~m} / \mathrm{s}$.

[25] However, in tropical cyclones, annulus of heavy rain with rates greater than $90 \mathrm{~mm} \mathrm{~h}^{-1}$ can be locally found within layer thickness as large as $4-5 \mathrm{~km}$ [e.g., see Houze et al., 2007]. From radiative transfer computations conducted at an incidence angle of $50^{\circ}$ and assuming a uniform rain cloud over the instrument field of view, Schulz [2002] estimated that a significant rain-induced bias in the L-band $\mathrm{T}_{\mathrm{B}}$ of approximately $\sim 6.5 \mathrm{~K}$ can be expected for an extreme case with a rain rate larger than $90 \mathrm{~mm} \mathrm{~h}^{-1}$ and a rain layer thickness of more than $9 \mathrm{~km}$. Nevertheless, even in the vicinity of the hurricane eyewall the columns of heavy rain only extend over a small portion of the SMOS footprint (which has an averaged diameter of $\sim 43 \mathrm{~km}$ ). For these cases when heavy and light rain will co-exist within the SMOS footprint, the actual rain impact should be therefore significantly smaller than the previous extreme estimate of $6.5 \mathrm{~K}$ due to the footprint spatial averaging. As found for SSM/I channels at 19 and $37 \mathrm{GHZ}$ [Wentz and Spencer, 1998] with $\sim 40 \mathrm{~km}$ footprint resolution, the 'beamfilling effect' reduces the rain impact by $\sim 40 \%$ in average. Assuming that this reduction factor can be as well applied to SMOS data, the L-band brightness temperature would be maximally biased by rain by $\sim 4 \mathrm{~K}$ in extremely heavy rain rate conditions and at an incidence angle of $50^{\circ}$. According to equation (2), the rain impact shall be approximately a factor 1.5 smaller at an incidence angle of $10^{\circ}$ than at $50^{\circ}$.

[26] Sea spray droplets impact at L-band can be modeled using the Rayleigh scattering approximation, as in the case of rain droplets, because of the small ratio of sea spray droplet diameters to electromagnetic wavelength. As discussed by Raizer [2007], a negligible impact of sea spray droplets on the brightness temperature is expected for electromagnetic wavelength longer than about $8 \mathrm{~cm}$. While sea spray layers generated above the ocean surface in hurricanes can affect radiometer observations for frequencies higher than $4 \mathrm{GHz}$, they shall be almost transparent at $1.4 \mathrm{GHz}$.

[27] Based on this review, we conclude (i) that the sensitivity of the ocean L-band brightness temperature half total power to wind speed shall be on the order of $0.3 \mathrm{~K} \mathrm{~m} \mathrm{~s}^{-1}$ for wind speed below $\sim 25 \mathrm{~m} \mathrm{~s}^{-1}$, (ii) it is weakly dependent on the incidence angle over the range $20^{\circ}-50^{\circ}$, (iii) neglecting the wind direction dependence may yield maximum $0.3 \mathrm{~K}$ amplitude errors in these conditions; (iv) neglecting the contributions of rain and spray to the L-band brightness temperature observed over the ocean at high winds shall be negligible in general except in very high rain rates for which maximum impact may reach $\sim 4 \mathrm{~K}$ and (v), atmospheric contributions from oxygen and water vapor can be corrected using a radiative transfer model with negligible errors with respect the expected magnitude of the wind-induced surface radio-brightness contrasts.

[28] While significantly less sensitive than the higher microwave frequencies, spaceborne L-band radiometer observations over the ocean are therefore very likely dominated by the varying impact of sea foam generated by breaking waves, which mainly depends on surface wind strength and sea state development.

[29] Therefore, the new spaceborne L-band observations should complement the information obtained from other spaceborne sensors. However, the existing empirical geophysical model functions for the wind excess emissivity at L-band and high winds has only been validated for wind speeds smaller than $\sim 25 \mathrm{~m} \mathrm{~s}^{-1}$, and as the presently available physical model-based GMFs strongly overestimates the excess emission, a new analysis of the wind-induced excess emission at L-band at high wind speeds is thus required.

\section{Study Data Sets}

[30] This section describes the data sets and processing used for the analysis of the SMOS L-band brightness temperature signatures over the Hurricane Igor.

\subsection{SMOS Brightness Temperatures and Processing}

[31] SMOS $T_{B}$ images are formed through Fourier synthesis from the cross correlations between simultaneous signals obtained from pairs of antenna elements. For this study, we used the SMOS Level 1B products, generated by the SMOS Data Processing Ground Segment (DPGS). The SMOS Level-1B product is the output of the image reconstruction of the observations and comprises the Fourier component of the brightness temperature in the antenna polarization reference frame, hence brightness temperatures. Level-1B corresponds to one temporal measurement, i.e., the whole field of view, one integration time, and is often called a 'snapshot' as for a camera. The brightness temperature images are further obtained from the so-called Level 1B brightness temperature frequencies by applying an inverse Fast Fourier Transform (IFFT) to the Level 1B brightness temperature Fourier coefficients using a Blackman spatial filter as described by Anterrieu et al. [2002]. The reconstructed brightness temperatures product at the top of the atmosphere is geolocated in an equal-area grid system (ISEA 4H9 - Icosahedral Snyder Equal Area projection) with an oversampled spatial resolution of about $\sim 15 \mathrm{~km}$. We consider here $\mathrm{T}_{\mathrm{B}}$ data reconstructed in the extended field of view (FOV) domain of the antenna for which the swath width is approximately $1200 \mathrm{~km}$ [see Font et al., 2010, Figure 6]. The actual spatial resolution of the reconstructed $\mathrm{T}_{\mathrm{B}}$ data varies within the $\mathrm{FOV}$ from $\sim 32 \mathrm{~km}$ at boresight to about $\sim 80 \mathrm{~km}$ at the edges of the swath $(43 \mathrm{~km}$ on average over the field of view). The probing earth incidence angle is ranging from nadir to about $60^{\circ}$ and the radiometric accuracy from $2.6 \mathrm{~K}$ at boresight to about $4-5 \mathrm{~K}$ on the swath edges. As the satellite moves, multiple observations of the same pixel at different incidence angles are obtained from successive snapshots. Earth grid points with less than 5 multiangular observations, as can be encountered at the extreme border of the swath, were removed.

[32] The L-band brightness temperatures measured by a downward looking radiometer such as that on board SMOS are significantly influenced by a number of radiation sources [Yueh et al., 2001; Font et al., 2010]. Among the most important sources of L-band brightness over the ocean are: (1) perfectly flat surface emission (with order of magnitude $100 \mathrm{~K}$ ); (2) atmospheric emission (on the order of $5 \mathrm{~K}$ including reflected downwelling and upwelling); 
(3) scattered galactic radiation incident at the surface (order of magnitude $10 \mathrm{~K}$ ); and (4) excess emission associated with the wind-driven surface roughness and breaking-wave generated foam (order of magnitude $10 \mathrm{~K}$, up to $20 \mathrm{~K}$ in gale force winds).

[33] By using the SMOS Level 2 radiative transfer forward model of scene brightness for each of these geophysical sources [Zine et al., 2008], we can estimate all but one of these contributions from the data in order to reveal individual residual sources $\Delta T_{B}$ of brightness contrast. To analyze SMOS signal over Igor and to reveal the impact of surface roughness and foam changes on the brightness temperatures at the radiometer, we therefore removed from the measurements all but the rough and foamy surface emission contributions. The necessary geophysical auxiliary data required to evaluate the different forward model contributions are obtained operationally at the SMOS measurement time and locations by the DPGS using products from ECMWF. Note that in the SMOS forward model [Zine et al., 2008], the evaluation of atmospheric contributions do not account for potential rain impact, which is hereafter neglected.

[34] To estimate the flat sea surface emission contribution, we used the OSTIA analyzed Sea Surface Temperature daily nighttime products [Stark et al., 2007] and we assumed the sea surface salinity (SSS) can be estimated by interpolating on SMOS data grid the monthly September climatology from the World Ocean Atlas 2005 [Boyer et al., 2006]. Note that the sensitivity of the brightness temperature to salinity is in general on the order of $\sim 0.8 \mathrm{~K} / \mathrm{psu}$ for warm waters above $28^{\circ} \mathrm{C}$. The expected climatological variability of SSS in the ocean area studied in that paper is below $0.1-0.2 \mathrm{psu}$. Very strong rain rates in calm sea conditions can however generate very significant local drops (4-5 psu) in the surface salinity. Nevertheless, these events are very local, with spatial scales on the order of $1 \mathrm{~km}$ and generally below $10 \mathrm{~km}$. At the spatial resolution of SMOS, the sensed effect would drop to maximum residual errors on the order of $\sim 0.2$ psu due to the spatial averaging effect. Moreover, in Tropical cyclone, the surface mixing by breaking waves is very intense so that we expect the freshwater skin layers generated by heavy rainfall to be very quickly disrupted and the SSS to adjust very rapidly with the surrounding water salinity. According to the expected $\sim 0.3 \mathrm{~K} /\left(\mathrm{m} \mathrm{s}^{-1}\right)$ and $\sim 0.8 \mathrm{~K} / \mathrm{psu}$ sensitivities of the L-band $\mathrm{T}_{\mathrm{B}}$ to wind speed and SSS, respectively, very large errors in the estimate of SSS on the order of $\sim 0.5$ psu shall therefore translate into maximum wind speed biases on the order of $1 \mathrm{~m} / \mathrm{s}$.

[35] An additional source of earth surface emitted brightness modification at L-band as measured from space is the polarization mixing (Faraday rotation), due to the electromagnetic wave propagation through the ionosphere in the presence of the geomagnetic field [Skou, 2003]. It can be either modeled from the knowledge of the ionospheric Total Electron Content (TEC) and magnetic field or avoided by using the first Stokes parameter $\mathrm{I}=\mathrm{T}_{\mathrm{H}}+\mathrm{T}_{\mathrm{V}}$, which is basically invariant by rotation. We chose here this alternative option and estimated the first Stokes surface roughness and foam-induced brightness temperature residual: $\Delta \mathrm{I}=\Delta \mathrm{T}_{\mathrm{H}}+\Delta \mathrm{T}_{\mathrm{V}}$.

[36] Finally, to reduce the instrument instantaneous radiometric noise which can vary from $2.6 \mathrm{~K}$ to $5 \mathrm{~K}$ for a single snapshot measurement as function of the position of the pixel within the swath, we averaged the SMOS multiangular measurements performed at a given location on earth to estimate an 'incidence-angle averaged' first Stokes brightness temperature residual generated by surface roughness and foam: $\overline{\Delta I}=\frac{1}{\theta_{\max }-\theta_{\min }} \int_{\theta_{\min }}^{\theta_{\max }} \Delta I(\theta) d \theta$, where $\theta$ is the earth incidence angle and $\left[\theta_{\min }, \theta_{\max }\right] \approx\left[10^{\circ}, 60^{\circ}\right]$. Note that in the remaining of the paper, we will consider the half total power: $\frac{\Delta I}{2}=\Delta\left(T_{H}+T_{V}\right) / 2$ and for clarity, we shall drop the overbar notation. Unless specified, $\Delta I$ will therefore always refer to the incidence angle-averaged half-power quantity. The noise-reduction approach through incidenceangle averaging is necessary in the context of SMOS data analysis for instantaneous events because of the low signalto-noise ratio for a single angle measurement. The approach is partly justified by the fact that a small incidence-angle dependence of the foam impact is expected at L-band in the range $0^{\circ}-50^{\circ}$ [Reul and Chapron, 2002; Camps et al., 2005; Yueh et al., 2010]. The incidence angle dependencies of the L-band brightness contrasts observed with SMOS at high winds will be nevertheless analyzed and discussed in the section 5 of the paper.

\subsection{NHC-BEST Track Data and Surface Wind Data Sets}

[37] Best storm track data for Igor were obtained from the Automated Tropical Cyclone Forecast system [Sampson and Schraeder, 2000] with products available at the NOAA National Hurricane Center (NHC). This data set includes hurricane eye location as function of time as well as maximum sustained surface wind speeds $V_{\max }$, radii of maximum winds $R_{\max }$, radii at 34,50 and 64 knots per storm quadrants, minimum sea level pressure etc..

[38] According to Pasch and Kimberlain [2011], observations in Igor include subjective satellite-based Dvorak technique intensity estimates from the Tropical Analysis and Forecast Branch (TAFB) and the Satellite Analysis Branch (SAB), and objective Dvorak estimates from the Cooperative Institute for Meteorological Satellite Studies/University of Wisconsin-Madison (CIMSS). Observations also include flight-level, stepped frequency microwave radiometer (SFMR), and dropwindsonde observations from flights of the 53rd Weather Reconnaissance Squadron of the U. S. Air Force Reserve Command (53WRS). Data and imagery from NOAA polar-orbiting satellites, including the Advanced Microwave Sounder Unit intensity estimates from CIMSS, the NASA Tropical Rainfall Measuring Mission (TRMM) and Aqua, the European Space Agency's Advanced Scatterometer (ASCAT), and DMSP satellites, among others, and radar observations from Bermuda were also useful in constructing the best track of Igor.

[39] In addition, we used $\mathrm{H}^{*}$ Wind surface wind analysis products [Powell et al., 1998] from the Hurricane Research Division (HRD) of the Atlantic Oceanographic and Meteorological Laboratory. SFMR data were obtained in Igor from an Air Force C-130 aircraft, starting on the 16th of September. For Igor hurricane, $\mathrm{H}^{*}$ wind analysis were only produced by HRD starting at that date.

[40] As a complementary surface wind data set, we consider the wind-forcing data used for the operational products of the NOAA/NWS/NCEP North Atlantic Hurricane Wind Wave forecasting system (NAH) [Chao et al., 2003; Chao 
and Tolman, 2001]. This surface wind model product is available at http://polar.ncep.noaa.gov/waves/ and is a blend of the Global Forecast System (GFS) products and of the NOAA/Geophysical Fluid Dynamic Laboratory (GFDL) hurricane model winds. The products are obtained four times a day: $00 \mathrm{Z}, 06 \mathrm{Z}, 12 \mathrm{Z}$, and $18 \mathrm{Z}$ with a current 0.25 degree resolution grid. These products are available for the complete period for which SMOS overpassed Igor, from the 11th to the 19th of September. Note that the latter model primarily assimilates the satellite-derived winds from the cloud motion sensing of the IR channels of the Geostationary Operational Environmental Satellite (GOES), as well as sea surface temperature observations [Soden et al., 2001]. To our knowledge, the SFMR wind and GPS dropwindsonde measurements used in the $\mathrm{H}^{*} \mathrm{WIND}$ products are not assimilated in the GFDL hurricane wind model.

[41] Both GFDL and H*WIND products, when available, were co-registered with SMOS data for each satellite overpass of Igor. The two-dimensional wind field structures at a given time were expressed in a reference frame centered on the Hurricane eye location, obtained from the time-interpolated NHC best track data. The two closest wind fields in time (before and after a SMOS overpass of Igor) were then linearly interpolated at the SMOS acquisition time. Four SMOS swaths intercepting Igor out of nine, the 17th and 19th of September, could be co-localized with available $\mathrm{H}^{*}$ WIND products. SMOS intercepted Igor at 0941 UTC and 2200 UTC the 17th Sep, and at 1005 UTC and 2219 UTC the 19th Sep. SMOS data acquired the 17th were thus co-localized with temporally interpolated fields obtained from $\mathrm{H}^{*} \mathrm{WIND}$ analyses available the $16 \mathrm{Sep}$ at $1930 \mathrm{UTC}$, the $17 \mathrm{Sep}$ at $1930 \mathrm{UTC}$ and the $18 \mathrm{Sep}$ at 0130 UTC. Minimum time lags between the closest $\mathrm{H}^{*} \mathrm{WIND}$ analysis and the SMOS acquisitions were therefore $10 \mathrm{~h}$ for the morning satellite pass of the 17th and of $2 \mathrm{~h} 30 \mathrm{mn}$ for the 17 th evening pass. $\mathrm{H}^{*}$ WIND analyses were produced by HRD for the 19th Sep at 0730 UTC, 1030 UTC, 1930 UTC and 2230 UTC, so that minimum time lags between SMOS acquisition and $\mathrm{H}^{*} \mathrm{WIND}$ products for that day were $\sim 30 \mathrm{mn}$ for both passes. Note also that only the $\mathrm{H}^{*} \mathrm{WIND}$ analysis of the 19th at 2230 UTC is based on SMFR data acquired within $\pm 2 \mathrm{~h}$ from SMOS acquisition.

[42] In practice, we found that the SMOS data as provided by ESA on an oversampled $\sim 15 \mathrm{~km}$ grid show much better resolution of the eyewall structure in several cases (see Figure 7) than on a reduced $50 \mathrm{~km}$ resolution grid. As the actual resolution of the instrument is varying from $\sim 30 \mathrm{~km}$ to $80 \mathrm{~km}$ as function of the position in the swath, this can be expected. Therefore, in an attempt to re-build SMOS-like sampling from the temporally interpolated $\mathrm{H}^{*}$ WIND or GFDL products; the latter fields were first spatially averaged at $\sim 50 \mathrm{~km}$ and were then re-interpolated at $15 \mathrm{~km}$ to be compared with SMOS data on the same grid.

[43] To illustrate the benefit and added-value of SMOS data with respect existing weather forecast models and spaceborne systems dedicated to surface wind measurements, we also considered wind speed products derived over Igor from ECMWF forecasts and from the METOP/ASCAT satellite scatterometer sensor.

[44] Finally, to tentatively separate the contributions to wind and rain-induced emission, when available, SMOS data were co-registered with rain rate estimates from either
TRMM/TMI, WindSat and SSMIS sensors. The data from these sensors were obtained from the Remote Sensing Systems web site.

\section{An Overview of SMOS Multiple Overpasses of Hurricane Igor}

[45] Residual wind-induced excess first Stokes brightness temperature parameter $\Delta I$ estimated from SMOS data during Hurricane Igor evolution from the 11th to the 19th of September are shown in Figure 3. Thanks to its large swath and frequent revisit time, SMOS satellite intercepted the hurricane 9 times during the 8-day period. The intensity and spatial distribution of the bright signal associated with the hurricane signature are seen to evolve significantly along the storm track. Note that when the hurricane is imaged on the swath borders (e.g., Figures $3 \mathrm{e}, 3 \mathrm{~g}$, and 3i), the noise level of the reconstructed brightness temperature is significantly larger and there are less multiangular brightness samples available than in the swath center. Uncertainty on $\Delta I$ increases for these cases.

[46] Superimposed contours of the $\Delta I$ for all the nine satellite overpasses of Igor are shown in Figure 4a. The associated contours for co-localized GFDL wind speed fields and $\mathrm{H}^{*}$ WIND observations are given in Figures $4 \mathrm{~b}$ and $4 \mathrm{c}$, respectively. In Figure $4 \mathrm{~d}$, we show as well the evolution of the maximum sustained surface wind speed $V_{\max }$ along the hurricane eye track as given in NHC Best track data. As illustrated, SMOS successively sampled Igor evolution as it developed from a Tropical Storm (11 Sep) into a Category 4 hurricane (13-15 Sep) and then weakened (17-19 Sep) to a category 1 hurricane on September 19. Four SMOS swath interceptions with Igor (13-15 Sep) were acquired during a period for which $V_{\max }$ reached values higher than $60 \mathrm{~m} \mathrm{~s}^{-1}$. As illustrated, the spatial and temporal evolution of SMOS $\Delta I$ is in general extremely consistent with the spatiotemporal evolution of the surface wind patterns from the GFDL model. In particular, the locii and patterns for the maxima in SMOS brightness temperatures correspond to the ones seen in the GFDL and $\mathrm{H}^{*}$ WIND surface winds. The spatial patterns of $\mathrm{H}^{*}$ WIND products are however significantly smoother than the ones from GFDL products or SMOS data: this is potentially an effect of the objective analysis method used to produce the $\mathrm{H}^{*}$ WIND fields. In general, the location of the wind and brightness temperature maxima coincide as the storm developed and appear to occur as expected on the right side quadrants of the frame moving with the storm.

\section{An Empirical Model for the Wind-Excess Emissivity of the Sea Surface at L-Band and High Winds}

[47] The ensemble data set consisting of $\mathrm{H}^{*} \mathrm{WIND}$ analyses co-registered with SMOS data is used hereafter to analyze the wind speed and incidence angle dependencies in the L-band surface emissivity residuals estimated from SMOS data. After temporal interpolation at the SMOS acquisition time and spatial averaging at the SMOS average footprint size, the ensemble of $\mathrm{H}^{*}$ WIND analyzed data available during these two days exhibit surface wind speeds reaching maximum values of $\sim 45 \mathrm{~m} \mathrm{~s}^{-1}$. To study the 


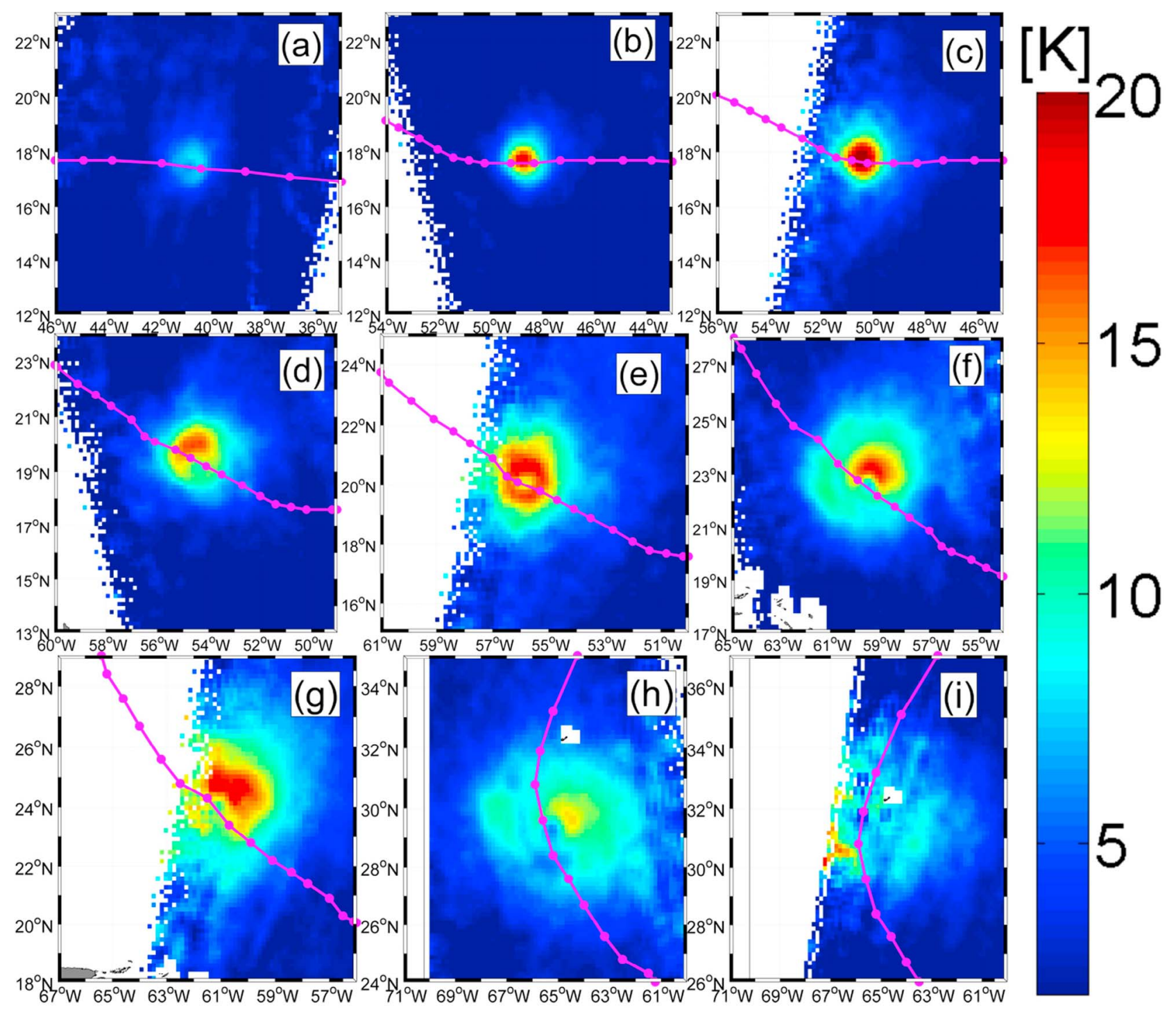

Figure 3. SMOS swath intercepts with Hurricane Igor from Sep 11 to 19. The color maps are indicating the values expressed in Kelvins of the wind-excess First Stokes Brightness Temperature parameter $\Delta\left(\mathrm{T}_{\mathrm{h}}+\mathrm{T}_{\mathrm{v}}\right) / 2$ after averaging locally the data over the multiple incidence angles measured by SMOS at (a) 2054 UTC $11 \mathrm{Sep}$, (b) 0855 UTC $13 \mathrm{Sep}$, (c) 2116 UTC $13 \mathrm{Sep}$, (d) 0918 UTC $15 \mathrm{Sep}$, (e) 2137 UTC $15 \mathrm{Sep}$, (f) $0941 \mathrm{UTC} 17 \mathrm{Sep}$, (g) 2200 UTC $17 \mathrm{Sep}$, (h) 1005 UTC 19 Sep, and, (i) 2219 UTC 19 Sep. The magenta dotted curves indicate the Best-track NHC/ATCF Hurricane eye location.

dependence of the L-band wind-excess emissivity with incidence angle, the estimated surface quantity $\Delta I$ from SMOS data were first classified as function of their incidenceangle value, collecting the data over $\pm 5^{\circ}$ incidence angle bins ranging from $15^{\circ}$ to $55^{\circ} . \Delta I$ data in each incidence angle bin were further averaged over $\pm 0.5 \mathrm{~m} \mathrm{~s}^{-1} \mathrm{H}^{*}$ WIND wind speed bins ranging from 8 to $45 \mathrm{~m} \mathrm{~s}^{-1}$.

[48] The results of the collected and bin-averaged data at an incidence angle of $45^{\circ}$ are shown in Figure 5a together with the superimposed PALS GMF. As illustrated, the linear PALS GMF function, which was derived from observations at wind speeds smaller than $\sim 28 \mathrm{~m} \mathrm{~s}^{-1}$, is found to be in very good agreement with the results of our analysis up to $\sim 22-25 \mathrm{~m} \mathrm{~s}^{-1}$. However, at higher wind speeds, the SMOS L-band brightness temperature residual is found to increase with the surface wind speed at a higher rate than the one predicted by the PALS GMF.

[49] The $\Delta I$ mean values averaged over the wind speed bins for the other incidence angle bins are further provided in Figure $5 \mathrm{~b}$. As illustrated, except for wind speeds smaller than about $25 \mathrm{~m} \mathrm{~s}^{-1}$, there is apparently a small dependence of the wind-excess emissivity at high winds on incidence angle. Regardless of incidence angle, $50 \mathrm{~km}$ resolution $T_{B}$ data increase quasi-linearly with the surface wind speed up to the hurricane wind speed threshold $\left(\sim 33 \mathrm{~m} \mathrm{~s}^{-1}\right)$. For almost all individual wind speed bins, the differences between $\Delta I$ acquired at incidence angles ranging from $\sim 10^{\circ}$ to $\sim 60^{\circ}$ are always smaller than $\sim 2 \mathrm{~K}$, which is below the SMOS instrumental noise level. Only the data at low incidence angles $\left(15^{\circ}\right.$ and $\left.25^{\circ}\right)$ and for wind speed smaller 

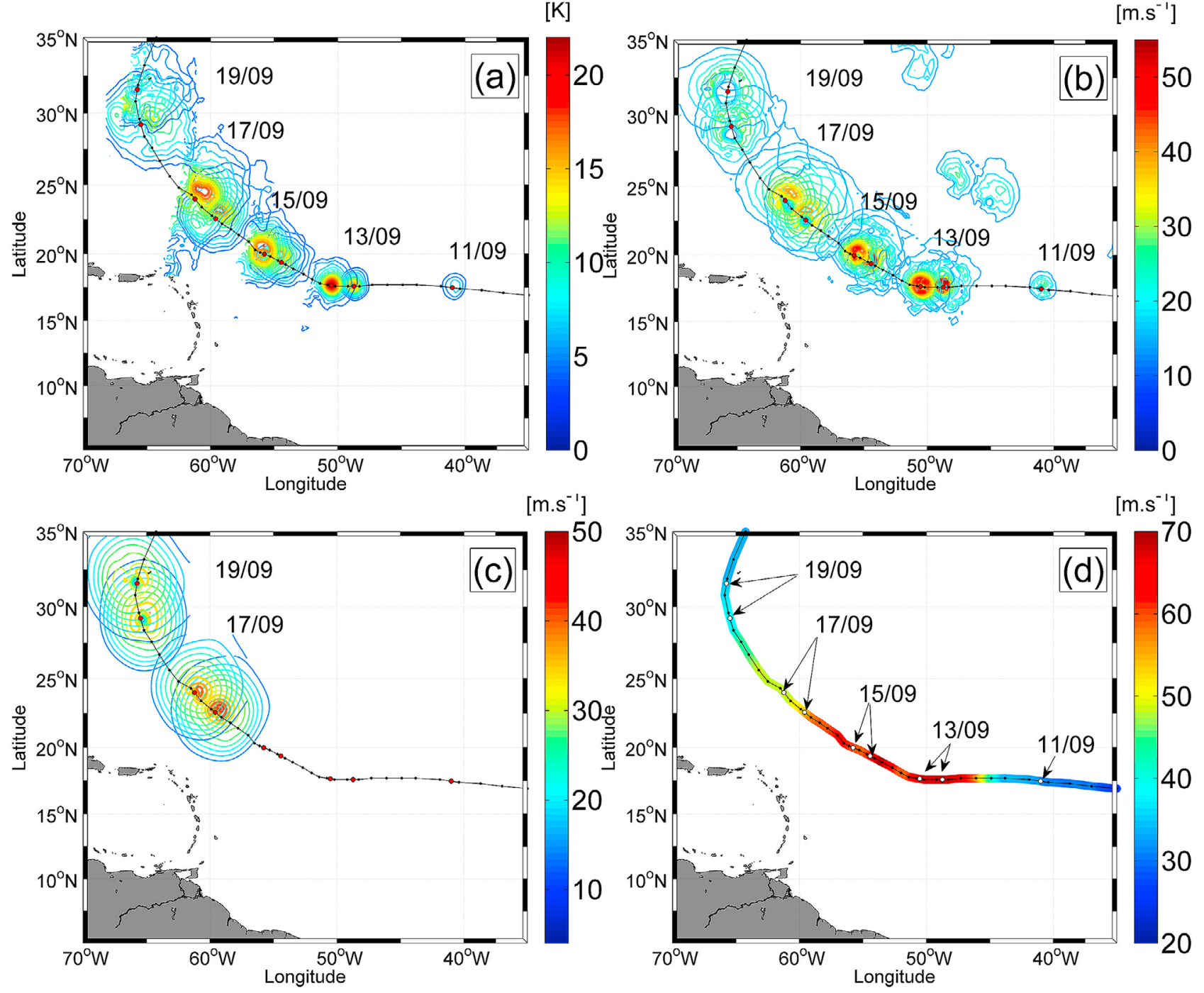

$\left[\mathrm{m} \cdot \mathrm{s}^{-1}\right]$
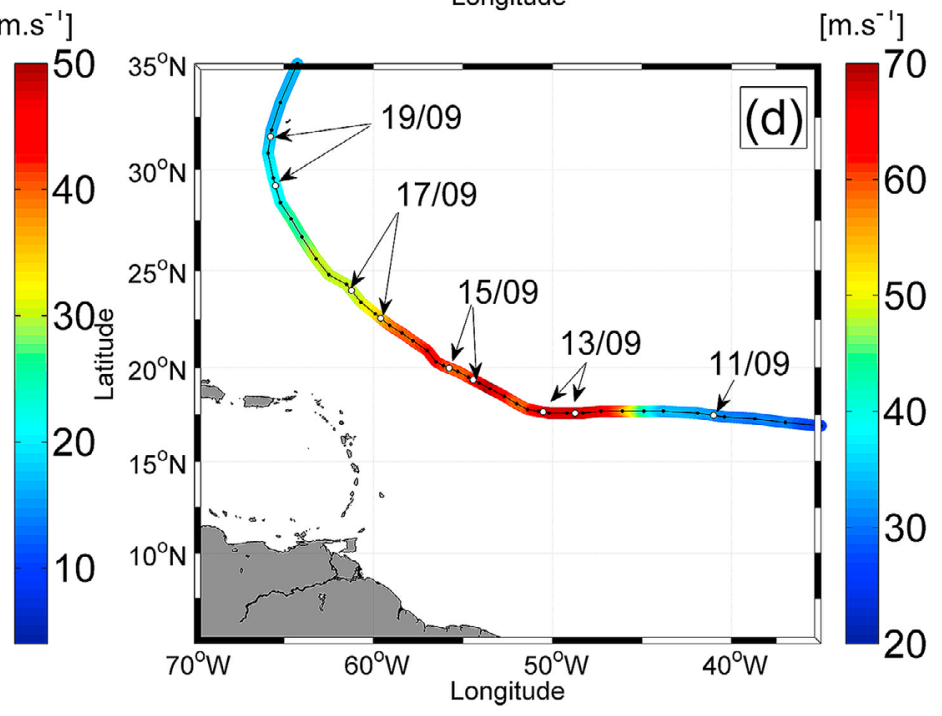

Figure 4. (a) Superimposed contours of the Wind-excess L-band First Stokes Brightness Temperature parameter $\Delta\left(\mathrm{T}_{\mathrm{h}}+\mathrm{T}_{\mathrm{v}}\right) / 2$ estimated from SMOS data during Hurricane Igor evolution from Sep 11 to 19. Contours are ranging from $4 \mathrm{~K}$ to $20 \mathrm{~K}$ by steps of $1 \mathrm{~K}$. Superimposed contours of the surface wind speed temporally interpolated at SMOS acquisition time from (b) GFS/GFDL hurricane model and (c) H*WIND analysis. Contours are ranging from $15 \mathrm{~m} \mathrm{~s}^{-1}$ to $50 \mathrm{~m} \mathrm{~s}^{-1}$ by steps of $2.5 \mathrm{~m} \mathrm{~s}^{-1}$. (d) Maximum sustained surface winds $V_{\max }$ along Igor track from the National Hurricane Center Best Track ATCF system. The white dots indicate the location of the Hurricane eye center at the SMOS acquisition time.

than $20 \mathrm{~m} \mathrm{~s}^{-1}$ exhibit slightly smaller $\Delta I$ values than at the other angles.

[50] The sensitivity of the $\Delta I$ to wind speed below $\sim 33 \mathrm{~m} \mathrm{~s}^{-1}$ is on the order of $0.35 \mathrm{~K} / \mathrm{m} \mathrm{s}^{-1}$ at most incidences which is slightly more than the PALS GMF $\left(0.29 \mathrm{~K} / \mathrm{m} \mathrm{s}^{-1}\right)$. The wind excess emissivity shows a fairly clear "leveling off" with increased wind speed above $32 \mathrm{~m}$ $\mathrm{s}^{-1}$, with an enhanced sensitivity of $\sim 0.75 \mathrm{~K} / \mathrm{m} \mathrm{s}^{-1}$. Given the weak sensitivity of the $\Delta I$ to incidence angle at most winds and the need to increase the instantaneous signal-tonoise ratio of SMOS data, in the following we neglect the small incidence angle dependence observed and consider the incidence-angle averaged $\Delta I$ quantity defined earlier. We further established an 'average' empirical relationship between SMOS $\Delta I$ s and the surface wind speeds, averaging
SMOS data at all incidence angles over $\pm 0.5 \mathrm{~m} \mathrm{~s}^{-1}$ $\mathrm{H}^{*}$ WIND wind speed bins. The following bi-linear function of surface wind speed $U_{10}$ was fit to SMOS estimates of radio-brightness contrasts $\Delta I$ with an averaged standard deviation of $\pm 1.8 \mathrm{~K}$ :

$$
\begin{array}{ll}
\Delta I=\frac{\Delta\left(T_{H}+T_{V}\right)}{2}=0.35 U_{10}-1.3, & U_{10} \leq 33 \mathrm{~m} \mathrm{~s}^{-1} \\
\Delta I=0.75 U_{10}-14.5, & U_{10} \geq 33 \mathrm{~m} \mathrm{~s}^{-1}
\end{array}
$$

In Figure 6, we show the equivalent wind-excess emissivity GMF (at an SST of $300 \mathrm{~K}$ ) determined from SMOS and $\mathrm{H}^{*}$ wind data over Igor.

[51] As illustrated, while more sensitive to wind speed than predicted by the PALS GMF, the SMOS GMF confirms the previously reported weaker sensitivity to surface wind 


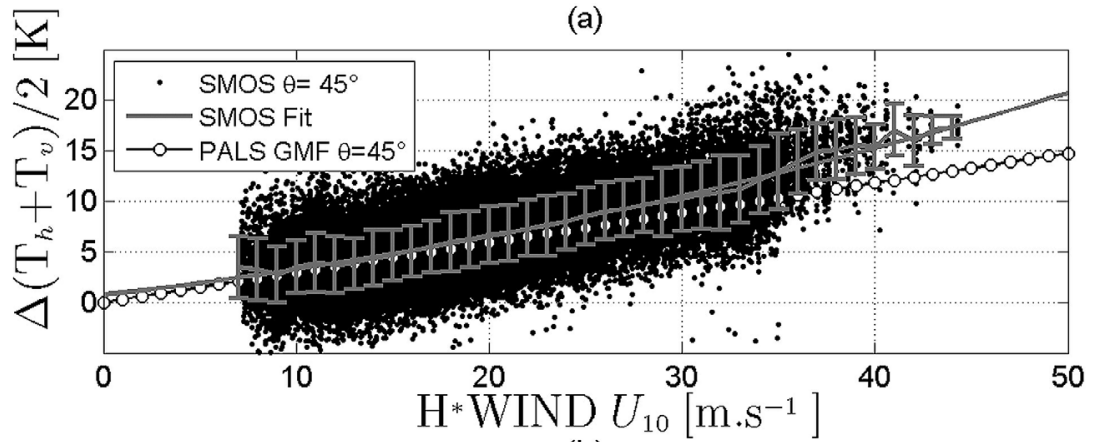

(b)

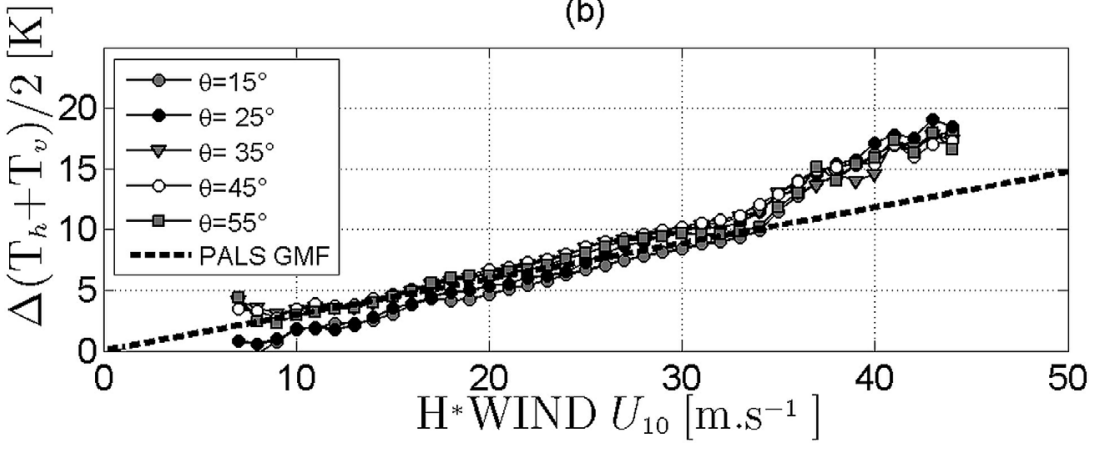

Figure 5. (a) SMOS $\Delta\left(T_{h}+T_{v}\right) / 2$ at an incidence angle of $45^{\circ} \pm 5^{\circ}$ as function of the co-localized $\mathrm{H}^{*}$ WIND analysis surface wind speed (black dots); PALS L-band GMF (white solid circles); Fit through the SMOS data averaged over $\pm 0.5 \mathrm{~m} \mathrm{~s}^{-1}$ wind speed bins \pm 1 standard deviation (gray curve). (b) Binaveraged wind-induced excess emissivity $\left(\varepsilon_{\mathrm{w}}\right)$ at L-band as a function of surface wind speed estimated from SMOS data at several incidence angles, ranging from $15^{\circ}$ to $55^{\circ}$. The PALS GMF function at L-band and $45^{\circ}$ incidence angle is also given (dash-dotted line).

speed at L-band than at C-band. As previously reported at C-band [Uhlhorn et al., 2007], we find that the windinduced excess emissivity at L-band is behaving differently below and above the hurricane wind speed threshold $\left(33 \mathrm{~m} \mathrm{~s}^{-1}\right)$. Our understanding of the physical mechanisms potentially responsible for this observed change in the sea surface radiometric properties at hurricane wind force will be discussed in section 8 .

\section{Analysis of the SMOS Retrieved Surface Wind Structures in Igor}

[52] The empirical model of equation (3) was next used to transform SMOS data into two-dimensional surface wind fields at each of the 9 satellite overpasses of Igor. In this section, we analyze the spatial and temporal structure of these fields and compare them to the GDFL hurricane model and $\mathrm{H}^{*}$ WIND fields.

[53] In Figures 7 and 8, we first show South-North and East-West sections through the surface wind fields given in the Hurricane eye centered coordinate system and for the nine overpasses. These representative sections reveal that the SMOS retrieved wind speed structure and its temporal evolution are in good general agreement with the one of the GFDL and $\mathrm{H}^{*}$ WIND fields. While local discrepancies in space and time can be found between the different products, the SMOS retrieved surface wind speed generally lie within the range of model and analyzed observation values. In particular, the SMOS wind field structure evolution during Igor rapid intensification phase between the 11th and the 15th (cases a to e in Figures 7 and 8) is in general in good agreement with the GFDL model predictions at $50 \mathrm{~km}$ resolution (gray curves). The maximum wind amplitude and the radii of winds greater than $\sim 17.5 \mathrm{~m} \mathrm{~s}^{-1}$

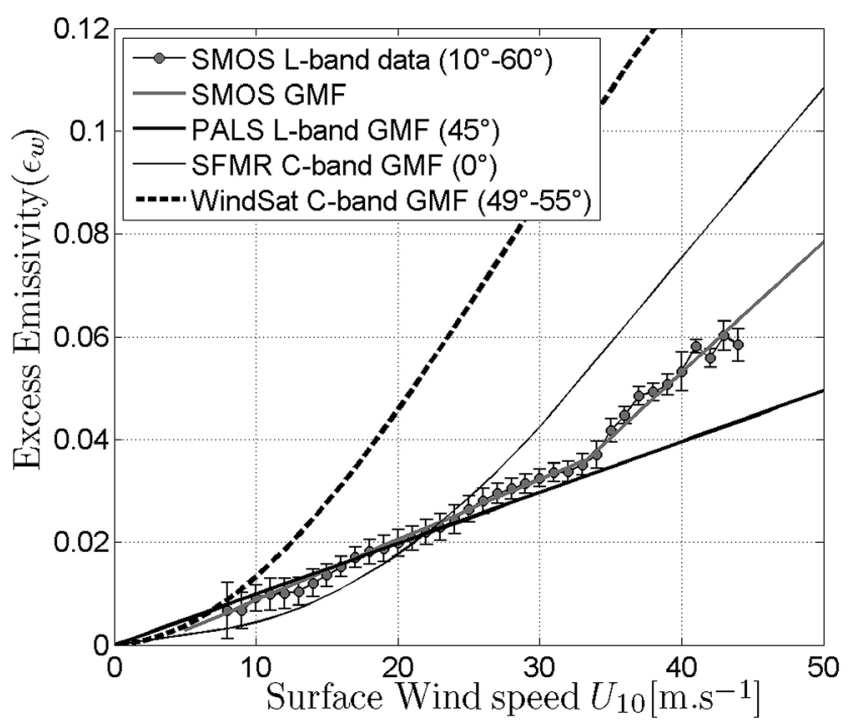

Figure 6. Wind-Excess Emissivity from SMOS L-band data averaged over incidence angles (gray solid circle) \pm 1 standard deviation. SMOS bi-linear Geophysical model function (gray lines), PALS L-band GMF, and SFMR C-band GMF. 

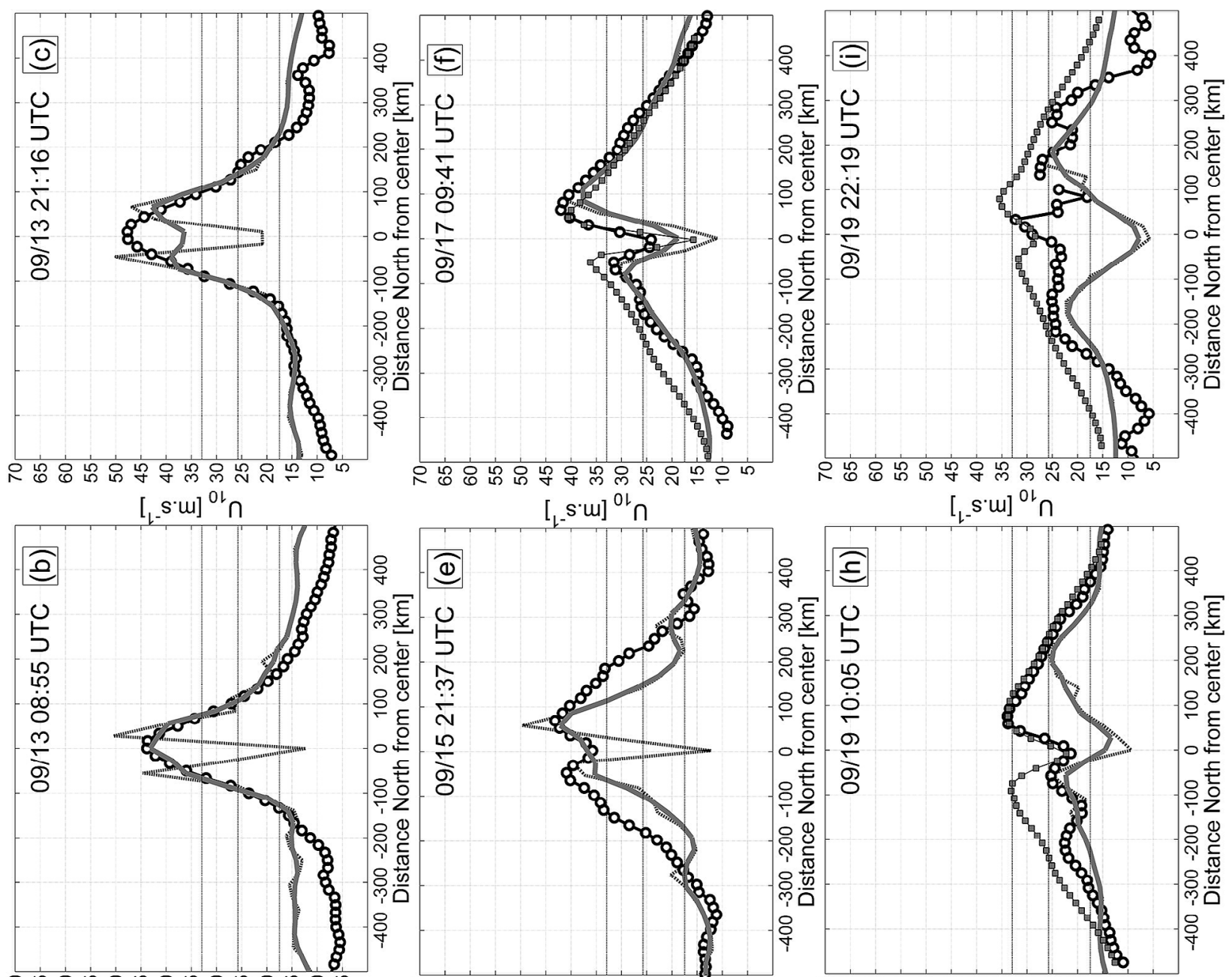

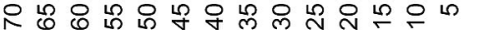

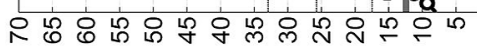
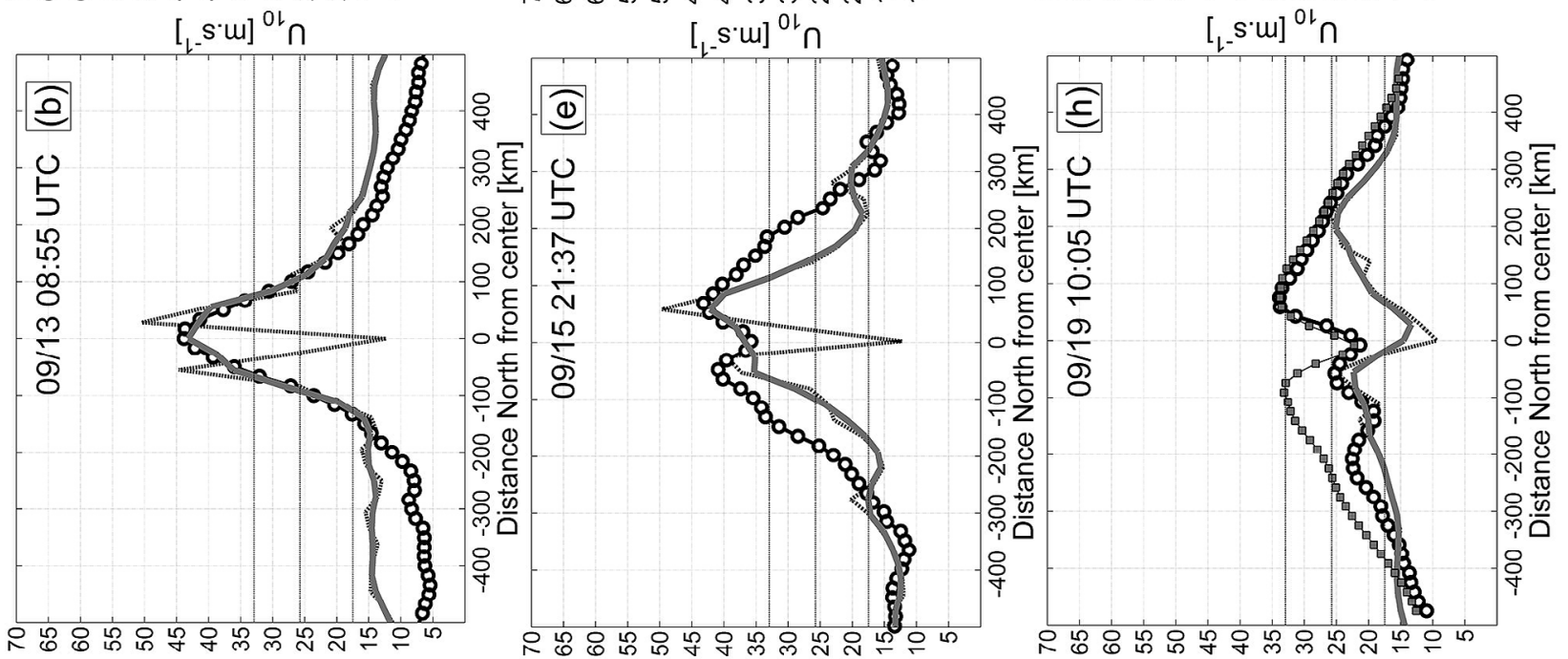

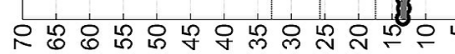

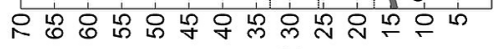

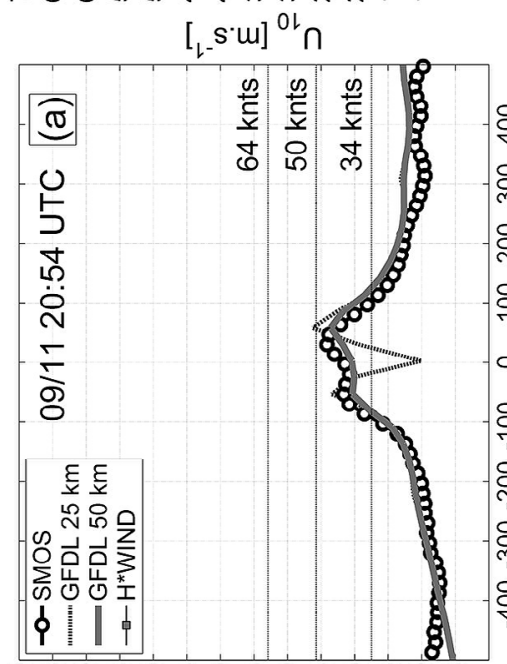

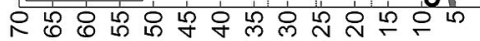

$$
\left.\left[L^{-} \cdot u\right]\right]^{0\llcorner} n
$$
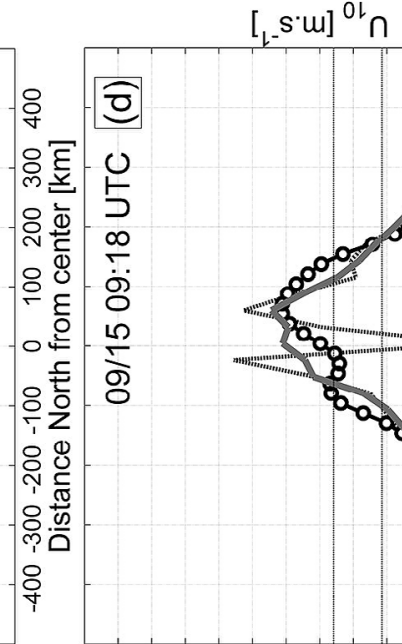

ㄴ.

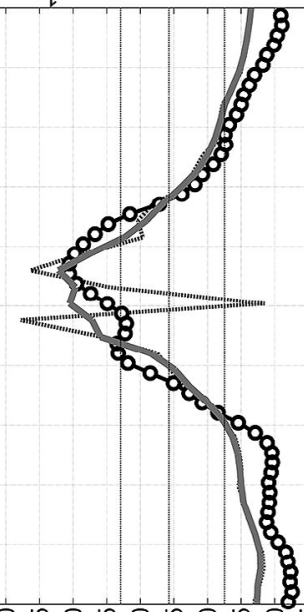

$\left[L_{-} s \cdot u\right]^{\text {oL }} n$

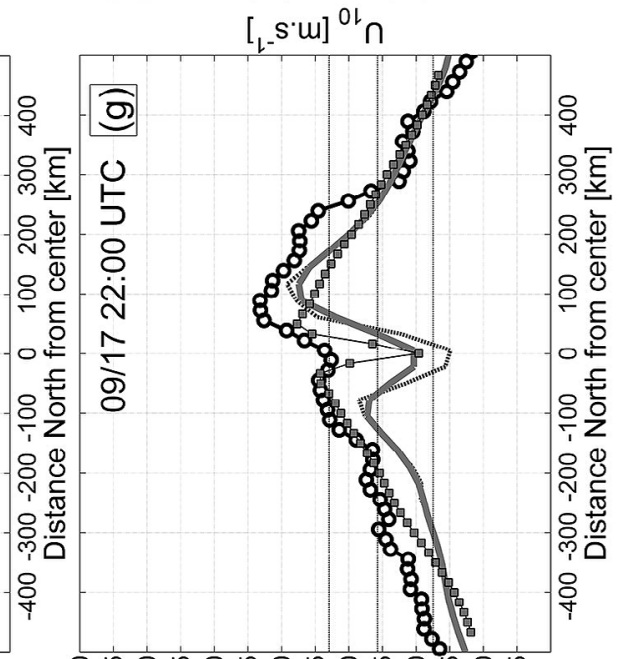

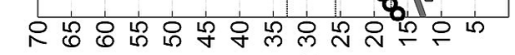


(34 knots), $25.7 \mathrm{~m} \mathrm{~s}^{-1}$ (50 knots) and $32.9 \mathrm{~m} \mathrm{~s}^{-1}$ (64 knots) coincide in most cases. The impact of the footprint averaging effect from $25 \mathrm{~km}$ to $50 \mathrm{~km}$ is illustrated by the much-better resolved eye structure in the GFDL products at $25 \mathrm{~km}$ resolution (dashed black curves) than at $50 \mathrm{~km}$ (gray solid curves). As expected, spatial averaging basically results in smoother and smaller wind speed gradients in the proximity of the hurricane eye. The spatial resolution of SMOS limits its ability to detect the surface wind field structure around the eye when the diameter of the latter is smaller than $\sim 50 \mathrm{~km}$.

[54] Over this period of rapid intensification, the largest discrepancies between SMOS retrieved wind fields and GFDL model predictions, which are the only 'validation' wind field products available for that period, are found for the case of the 15 Sep at 21:37 UTC (case e). In both SouthNorth and East-West sections, SMOS winds in the outer region of the eyewall clearly exhibit larger radii than in the GFDL model forecasts. Both the NHC Tropical Cyclone report for Igor [Pasch and Kimberlain, 2011], and the animation of the Morphed Integrated Microwave Imagery at $85 \mathrm{GHz}$ [Wimmers and Velden, 2007] which is available at Cooperative Institute for Meteorological Satellite Studies, reveal that Hurricane Igor underwent an Eyewall Replacement Cycle (ERC) beginning on 15 September morning. Previous studies [e.g., Tenerelli and Chen, 2002; Willoughby, 2007] show that the smaller inner eyewall deteriorate and became replaced by a much larger outer eyewall during the ERC process. As will be shown further in Figure 10, NHCbest track estimates of both radii at 34 and 50 knots clearly exhibit a step increase late on 15 September. We did not observed such increase in the GFS/GFDL model 6 hourly forecasts during that day. As discussed in Willoughby [2007], eyewall replacements are probably the most difficult phenomena to model and the accuracy of the GFDL forecasts might be questionable for that case.

[55] As Igor evolved and progressively weakened to a category 1 hurricane (Figures $7 \mathrm{f}-7 \mathrm{i}$ ), the eye diameter increased and SMOS data better captured the wind field structure around the eye. On the 17th (Figures $8 \mathrm{f}$ and $8 \mathrm{~g}$ ), SMOS retrieved wind speed fields apparently present an higher North-South asymmetry around the eye than the $H^{*}$ WIND products. For the 19th overpasses (cases $h$ and i), SMOS retrieved wind speed exhibit a greater radial variability than the two other fields but generally lie within the model and analyzed observation values. Here again, stronger North-South and East-West asymmetries are found in the SMOS wind than in the other products.

[56] Another view of the 2D wind field structure over Igor is provided in Figure 9, where we show the maps of SMOS winds in knots superimposed with the contours of the surface wind speed at 34, 50 and 64 knots for GFDL model and for $\mathrm{H}^{*} \mathrm{WIND}$ products. As illustrated, the previous findings based on specific sections across Igor are confirmed. In general, the spatial distributions of the SMOS retrieved surface wind speed are consistent with the GFDL and the $\mathrm{H}^{*}$ WIND wind speed products, particularly when the
Hurricane is imaged on the center of the swath (cases a to d, $\mathrm{f}$ and $\mathrm{h}$ in Figure 9). While this is not systematic, there are three overpasses in which the hurricane is imaged on the border of the swaths (cases e, $g$ and i) and for which the spatial extents of the SMOS winds higher than 34 and 50 knots are larger than the ones given by the GFDL model or by the analyzed observation products. Note that the SMOS products also tend to exhibit a higher azimuthal variability around the eye centers than the $\mathrm{H}^{*}$ WIND products as the hurricane weakened. This is particularly evident for the winds higher than 50 knots.

[57] A more compact view of these results is provided in Figure 10, where we show the temporal evolution of the median values of the radii at 34, 50 and 64 knots evaluated over the four storm quadrants for the different wind speed products. For each SMOS overpass of Igor, radial sections from the storm center were made across the wind fields every $20^{\circ}$ in azimuth, ranging from $0^{\circ}$ to $360^{\circ}$. The maximum radii at 34, 50 and 64 knots were evaluated at each radial section and the median and standard deviation values of each radius were finally estimated over the four quadrants. Figure 10 clearly illustrates that the temporal evolution of the surface wind field structure of the hurricane is, on average, well restituted by SMOS data. In particular, the temporal rate of growth of the three radii as Igor developed and their magnitude are in good agreement with the other products. The values of the median radii at 34 knots estimated from SMOS products are found to lie in between the GFDL model estimates at $50 \mathrm{~km}$ resolution and the NHC best-track estimates. The differences between SMOS radii and the other data set estimates are, in average, within $\pm 25 \mathrm{~km}$, which is expected given the SMOS instrument $\sim 50 \mathrm{~km}$ average spatial resolution. The 64 knots radii estimated from SMOS data from 15 to 19 Sep seem however most of the time greater by $\sim 30-50 \mathrm{~km}$ than the GFDL, $\mathrm{H}^{*}$ WIND or NHC best track estimates.

[58] For the evening overpass of the 15 th (see case e in Figures 7-9), the spatial extents of winds higher than 34, 50 and 64 knots were previously found to be significantly higher in SMOS product than in the GFDL model. Apparently, the step increase reported in the SMOS 34 and 50 knots radii from the 15 th morning to evening overpass is consistent with the one observed in the NHC best track estimates. Conversely, the GFDL radii estimates are decreasing over that period of time. As discussed earlier, these differences are potentially associated with the occurrence of a badly modeled eye replacement cycle process.

[59] Another important characterization of the wind field structures in hurricane that can be extracted from SMOS data includes estimates for the values and radii of the maximum wind speed. We show in Figure 11a the temporal evolution of the maximum wind speed along Igor track estimated from an ensemble of wind speed products. This ensemble includes the NHC maximum sustained wind speed, the maximum wind speed estimates from GFDL hurricane model at $25 \mathrm{~km}$ and $50 \mathrm{~km}$ spatial resolution, from the SMOS and H*WIND

Figure 7. (a-i) South-North sections through Igor hurricane of SMOS retrieved wind speed (white solid circles), GFDL surface wind speed model at $25 \mathrm{~km}$ resolution (black dash-dotted curves), at $\sim 50 \mathrm{~km}$ resolution (gray curves) and of $\mathrm{H}^{*}$ Wind analysis products (gray solid squares). Note that the $\mathrm{H}^{*} \mathrm{WIND}$ products were spatially averaged at $50 \mathrm{~km}$ and interpolated on the SMOS data grid (gray solid squares). The horizontal dashed lines in each plot are representing the wind speed levels at 34,50 and 64 knots. 


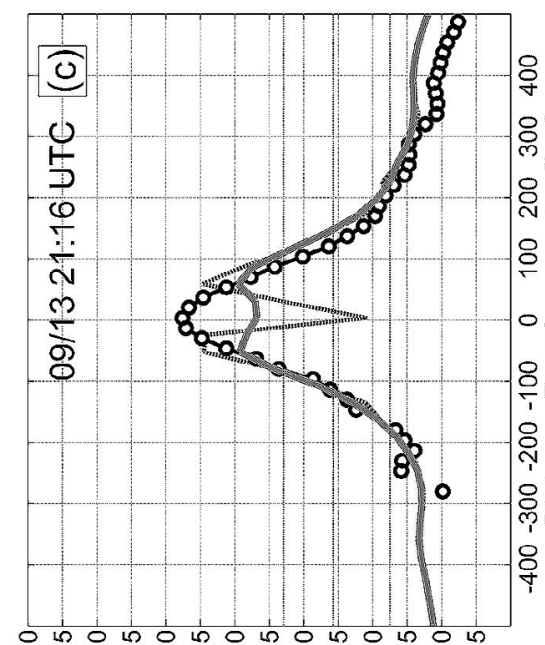

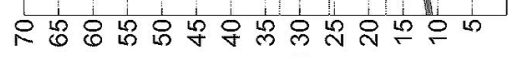

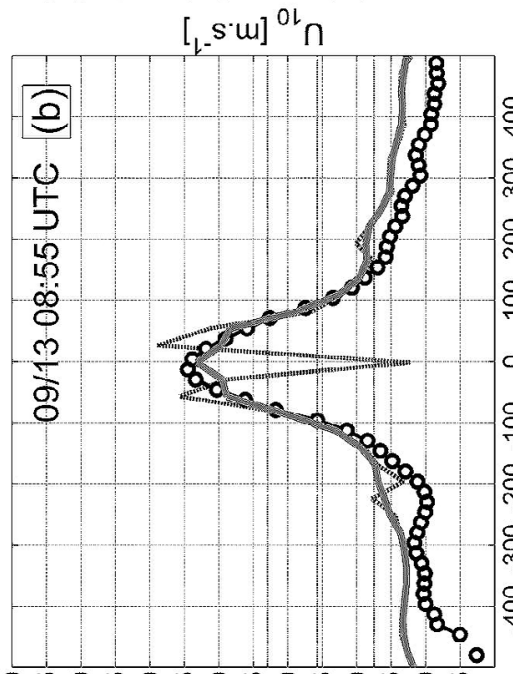

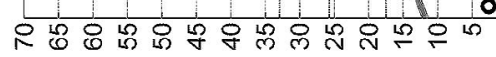
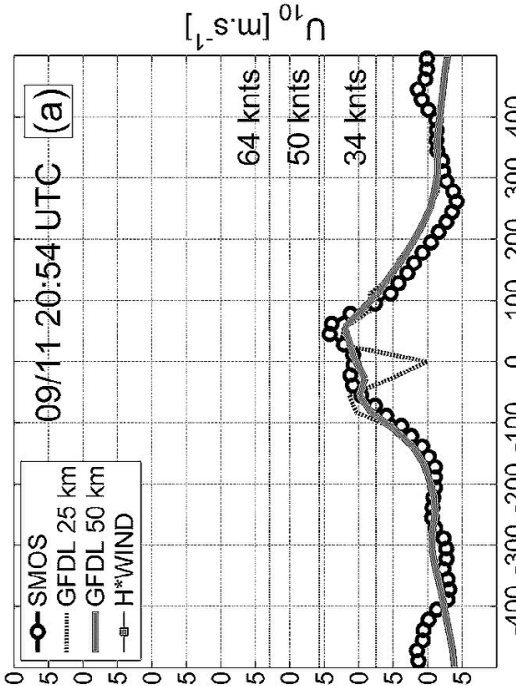

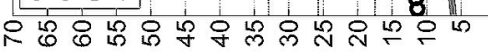

$$
\left[{ }_{\text {L- }} \mathrm{s} u\right]^{\mathrm{ol}} \mathrm{n}
$$

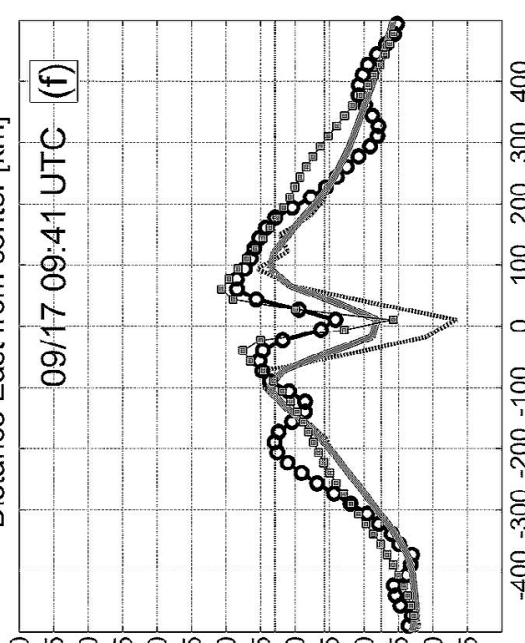

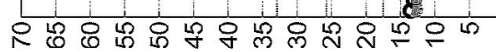
$\left[{ }_{l-} s^{*} m\right]^{0 l} n$

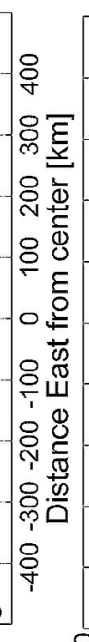

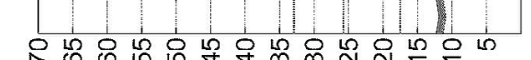

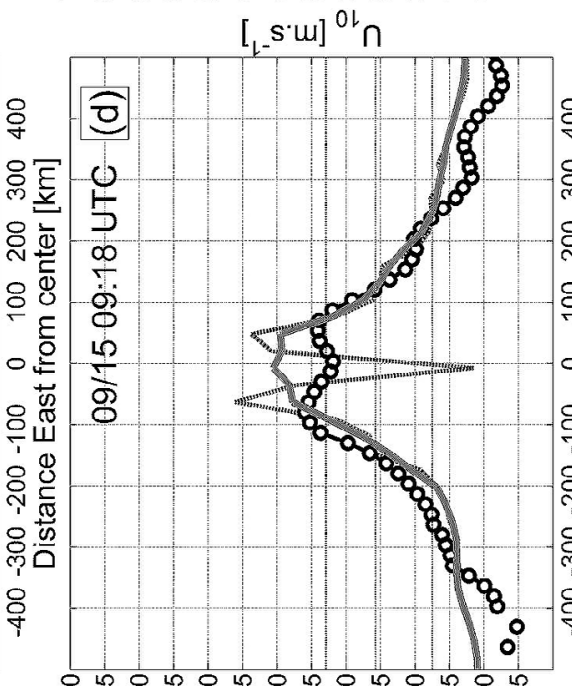

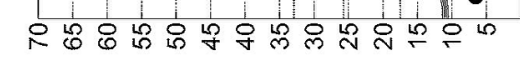
$[\mathrm{l}-\mathrm{s} \cdot \mathrm{m}]^{0 .} \mathrm{n}$

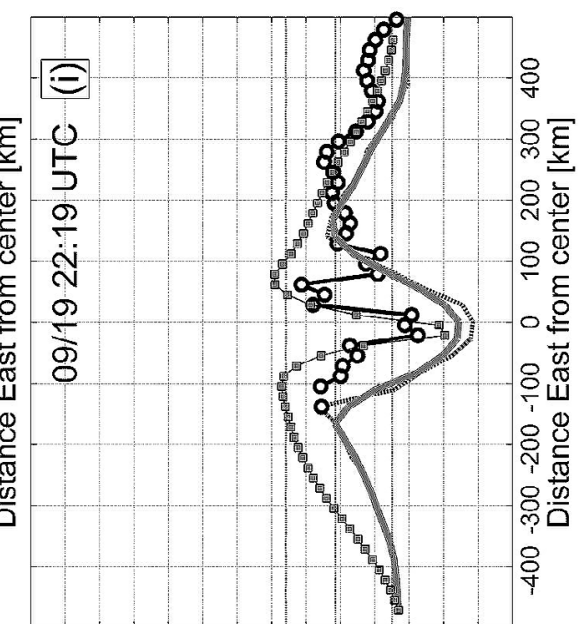

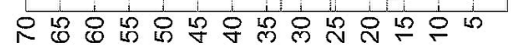

$$
\left[{ }_{1}-s^{\prime} \cdot m\right]{ }^{01} n
$$

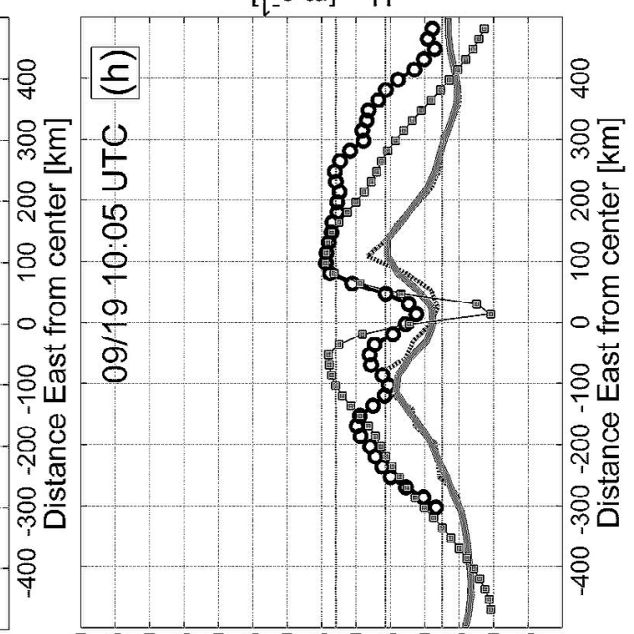

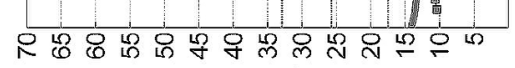
$\left[{ }_{L} s \cdot m\right]{ }^{0 l} n$

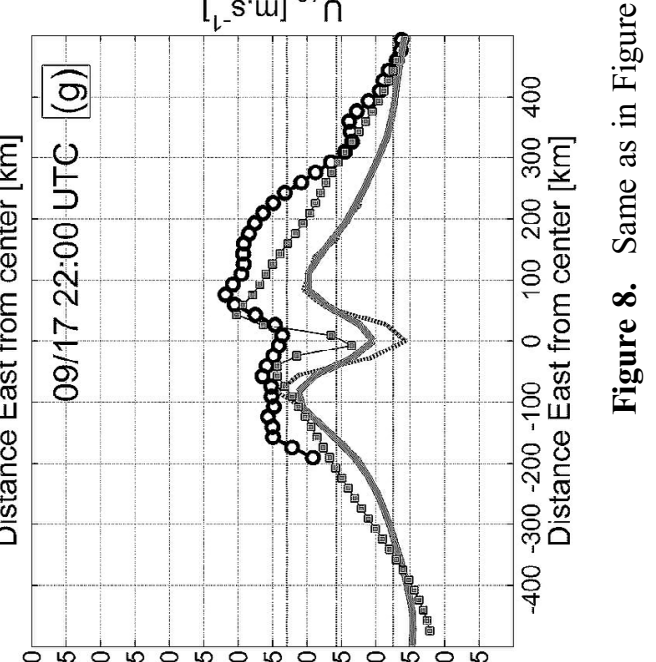

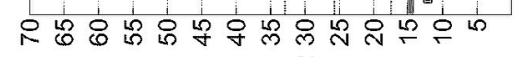
$\left[{ }_{L} \mathrm{~s} \cdot \mathrm{w}\right]{ }^{0 \mathrm{l}} \mathrm{n}$ 


\section{m}

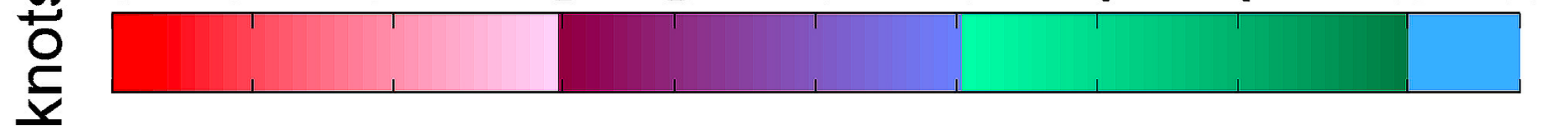

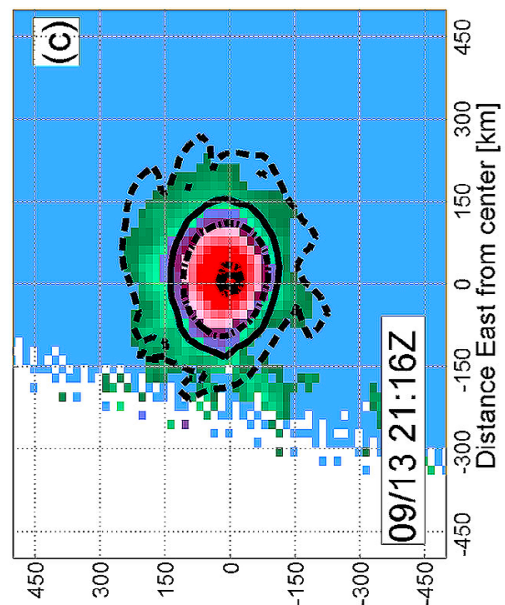

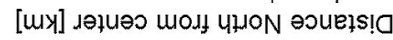

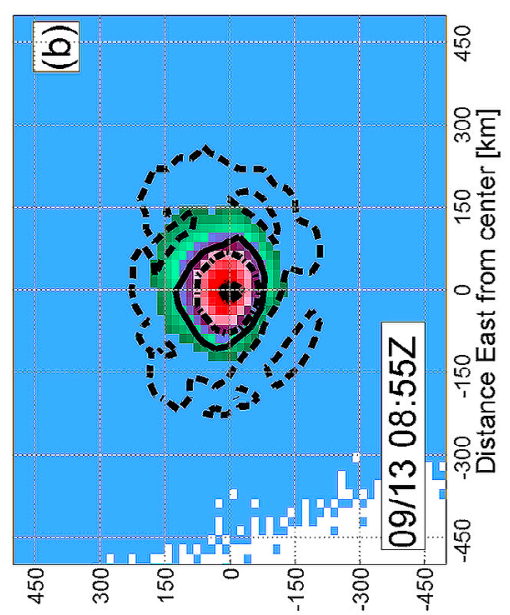

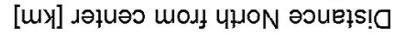

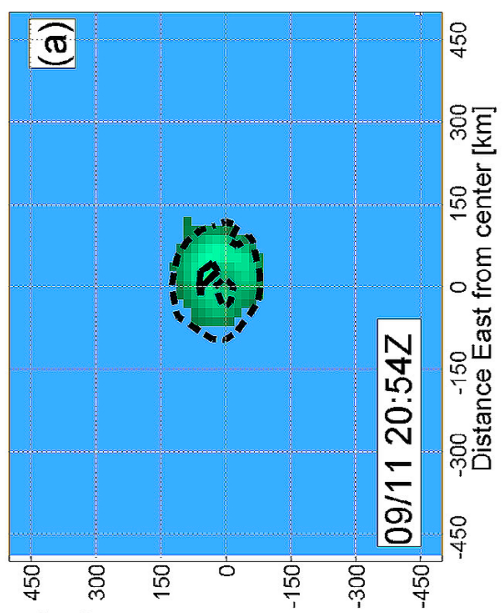

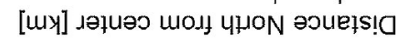

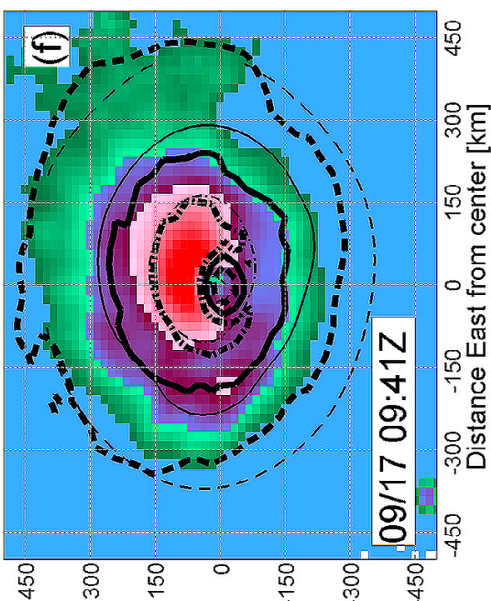

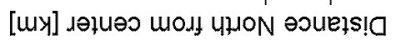

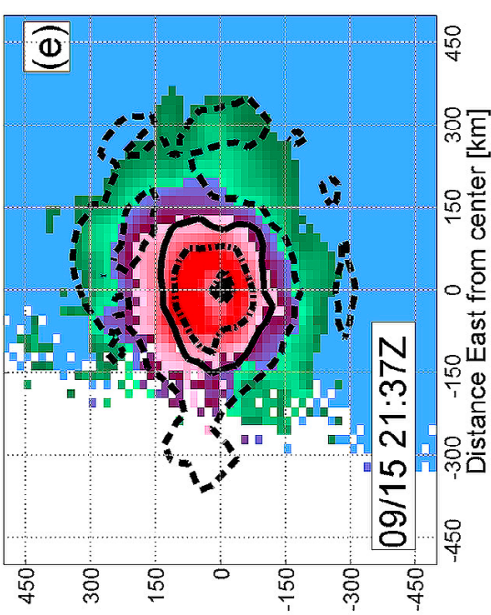

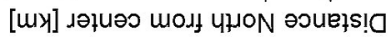

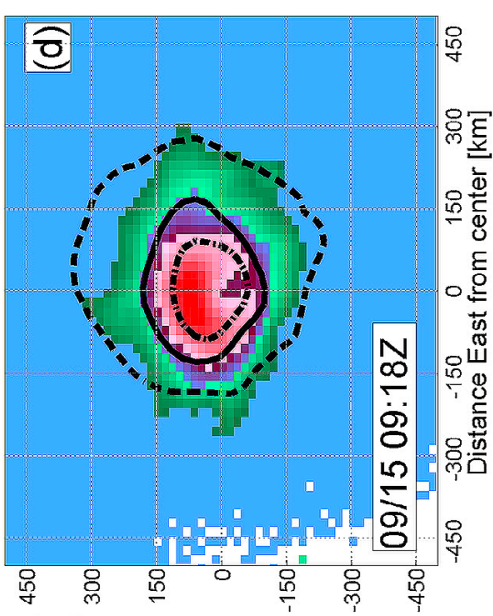

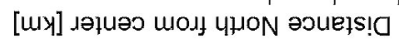

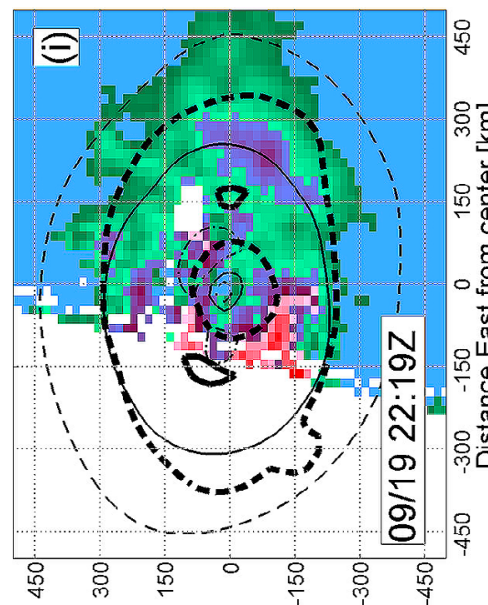

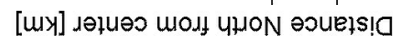

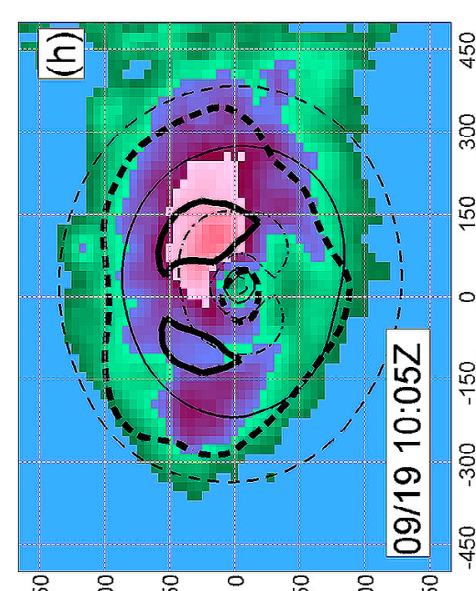

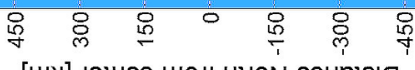

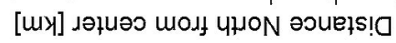

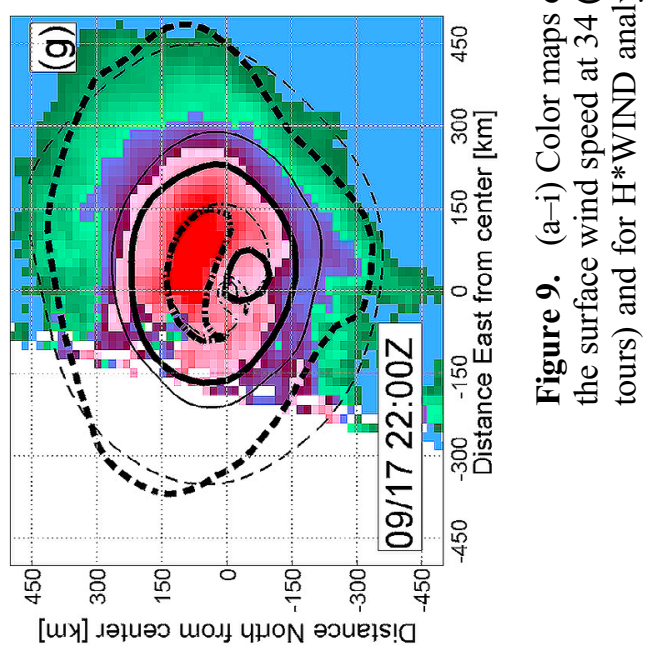


(a) 34 knots

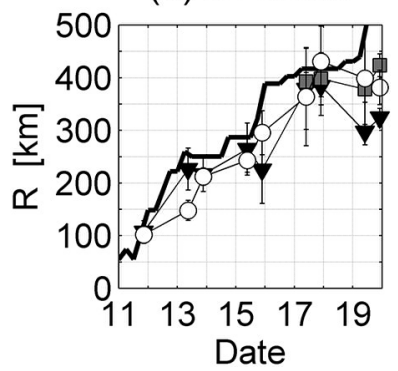

(b) 50 knots

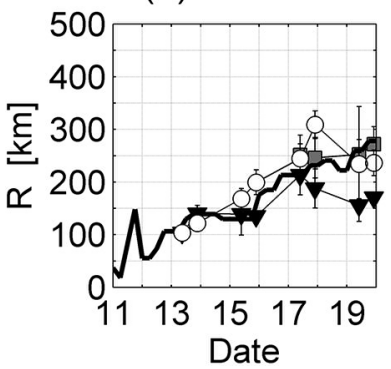

(c) 64 knots

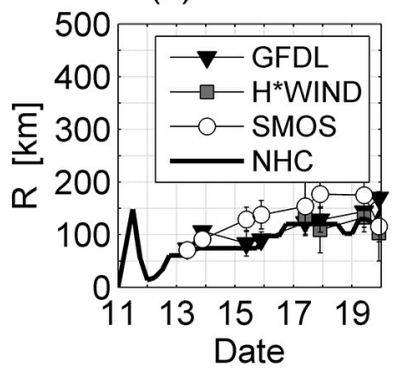

Figure 10. Median values of the surface wind speed Radii evaluated over the four Storm quadrants as function of days at (a) 34 knots, (b) 50 knots and (c) 64 knots. Symbols for the radii from the different wind products are: GFDL model (solid black triangles), H*WIND products (gray squares), SMOS estimated winds (solid white circles) and NHC/ATCF best-track estimates (thick black curves).

products as well as those extracted from ECMWF and METOP/ASCAT wind speed products.

[60] Note that Hurricane surface winds are strongly dependent on the averaging time attributed to the wind observations, the roughness of the underlying surface, and height of the wind measurements. The NHC best track maximum sustained surface wind is defined as the maximum 1 -min wind that might be observed at a height of $10 \mathrm{~m}$. Here, all the other wind products are also referred to the $10 \mathrm{~m}$ height. The $\mathrm{H}^{*} \mathrm{WIND}$ averaging time is also $1 \mathrm{~min}$, so that the SMOS retrieved wind speeds, by construction, were calibrated based on a $1 \mathrm{~min}$ averaging period. However, SMOS spatial resolution is at best $\sim 30 \mathrm{~km}$ at nadir, and most of world's operational centers outside of the U.S. consider the intensity to be defined by the maximum 10 -min wind, which may be more consistent with the spatial resolution of SMOS. Therefore, all wind speed value derived based on a $1 \mathrm{~min}$ averaging period were adjusted to the $10-\mathrm{min}$ standard. The relation of $1-\mathrm{min}$ to $10-\mathrm{min}$ averaged wind speed is that the latter is $12 \%$ smaller (http://www.nhc.noaa. gov).

[61] As illustrated, maximum 10-min winds retrieved from SMOS data during Igor reached $\sim 41 \mathrm{~m} \mathrm{~s}^{-1}$. During the rapid intensification phase of Igor (from the 11th to the 16th), maxima in SMOS winds exhibit values that lie in between the $25 \mathrm{~km}$ and $50 \mathrm{~km}$ resolution GFDL model products. As the hurricane weakened (17th to 19th), SMOS maximum winds decrease at a smaller rate than that reported

(a)

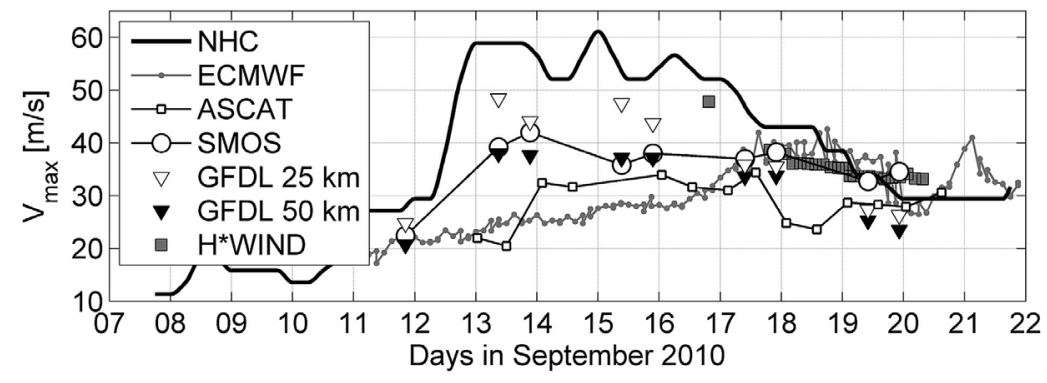

(b)

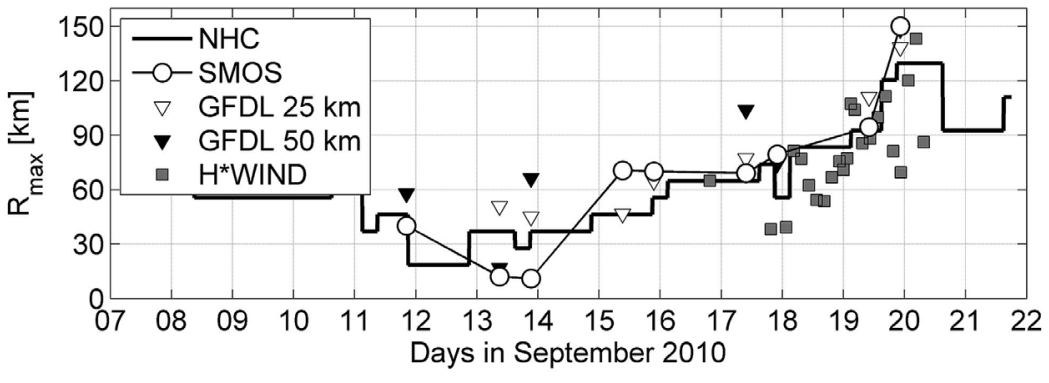

Figure 11. (a) Temporal evolution along Igor track of the maxima in SMOS retrieved surface winds (white solid circles), maximum sustained surface winds $\mathrm{V}_{\max }$ from NHC/ATCF (black curve), from GFDL Hurricane model at $0.25^{\circ}$ resolution (black solid triangles) and from $\mathrm{H}^{*}$ Wind analysis (gray solid squares). All wind speed values are 10-min wind. (b) Corresponding Radii of the maximum wind and of the location of SMOS maximum $\Delta(\mathrm{Th}+\mathrm{Tv}) / 2$. 
in NHC maximum sustained wind speed or in GFDL model at both resolutions. Nevertheless, the predicted maximum winds are in good agreement with the $\mathrm{H}^{*} \mathrm{WIND}$ estimates. For this hurricane, ECMWF products completely miss the step change in maximum surface winds during Igor rapid intensification and its temporal evolution up to the 17th. Similarly, maximum values in ASCAT wind products at $12.5 \mathrm{~km}$ never exceed $35 \mathrm{~m} \mathrm{~s}^{-1}$ and are unable to reproduce the hurricane maximum wind temporal evolution as seen in either NHC, GFDL model and SMOS products.

[62] Finally, the radius of maximum wind speed was evaluated along the storm track for each wind speed product and the results are shown in Figure 11b. The maximum wind radius estimated from SMOS winds are found to be in good agreement with the NHC best-track maximum wind radius estimates, in general to within $\pm 25 \mathrm{~km}$. For the 13th September SMOS overpasses of Igor, the NHC best-track estimates of $R_{\max }$ are smaller than $45 \mathrm{~km}$ : this is below the actual spatial resolution of SMOS and the wind structure around the eye is not correctly resolved by the instrument in these cases.

\section{Discussion}

[63] In developing our L-band GMF function, the windinduced surface brightness temperature at L-band was calculated and coregistered with simultaneous surface wind speed estimates interpolated from objectively analyzed $\mathrm{H}^{*}$ WIND winds up to $45 \mathrm{~m} \mathrm{~s}^{-1}$. Note that fundamentally, our model neglects (i) the potential impacts of the varying sea state on the brightness temperature and (ii) the potential impact of rain on the measurements. Both effects can be sources of errors in the wind speed retrieval from SMOS data. They are successively discussed in the following.

\section{1. $\mathbf{T}_{B}$ Dependencies on Sea State}

[64] At L-band, we found an average linear increase of the wind induced half total power brightness of $\sim 0.35 \mathrm{~K} / \mathrm{m} \mathrm{s}^{-1}$ up to the Hurricane Force $\left(\sim 32 \mathrm{~m} \mathrm{~s}^{-1}\right)$, followed by a more sensitive quasi-linear growth of $\sim 0.75 \mathrm{~K} / \mathrm{m} \mathrm{s}^{-1}$ as the wind speed exceeds that threshold.

[65] The observation of a step change in sea surface microwave emissivity with wind speed at hurricane force was also reported from SFMR data at C-band by Uhlhorn et al. [2007]. As discussed by Chen et al. [2007], there are compelling evidence that the physical nature of air-sea interaction is markedly altered when wind speeds exceed hurricane force. At wind speeds greater than about $33 \mathrm{~m} \mathrm{~s}^{-1}$, the drag coefficient reaches a saturation point and remains relatively constant [Powell et al. 2003; Donelan et al. 2004] or even decreases [Jarosz et al., 2007]. Donelan et al. [2004] attributed a change in flow characteristics leading to saturated aerodynamic roughness to the airflow separation mechanism resulting from continuous wave breaking, where the flow is unable to follow the wave crests and troughs (as shown by Reul et al. [2008]). As most of the wind stress is in general supported by surface waves with a wavelength that is less than typically 10-20 m, the "leveling off" of the drag coefficient at hurricane force suggests that the density of surface wave breaking events with wavelength smaller than this cutoff scale is also saturated. Consequently, the change in sensitivity of the SFMR's C-band and SMOS's L-band emissivity measurements with wind speed at hurricane force may be associated with an increase in breaking wave density of the largest scale waves.

[66] According to equation 1, the quasi-linear increase in sea surface emissivity at L-band with increasing wind speed above hurricane force is in apparent contradiction with an expected cubic wind speed dependence in the whitecap coverage [Monahan and O'Muircheartaigh, 1980]. Similar linearity in the foam coverage dependence with wind speed was also found indirectly by Quilfen et al. [2006] from altimeter C-band measurements in a hurricane. The foam contribution was identified as the main process to maintain altimeter measurements sensitivity at very high wind speed. This assumption was used to derive an empirical foam coverage from Jason C-band measurements over tropical cyclones Isabel. As found, the estimated foam coverage evolves quasi-linearly as function of wind speed, with a similar magnitude than the empirical foam coverage estimates for actively breaking waves [Bondur and Sharkov, 1982]. Note that in establishing their empirical model for the whitecap coverage as function of wind speed, Monahan and O'Muircheartaigh [1980] considered both "Stage A" feature that are due to actively breaking waves, and "stage B" features consist of the "fossil foam" or "foam rafts" that remained in the wake of a stage A breaker. This further suggests that $\mathrm{C}$ and L-band microwave radiation emitted by the ocean surface at high winds is dominated by the impact of actively breaking large scale waves.

[67] From a scientific standpoint, additional understanding of the sea surface radiometric properties can also be gained from the use of the hydrodynamic/electromagnetic model of equation (1). As found, when integrating the model over all surface wave scales breaking at the surface, the model of equation (1) thus significantly overestimates the reported wind-excess emissivity at L-band. A cutoff wavelength was therefore added in the model to artificially suppress the contributions from the smaller breaking wave scales generating foam layers with thicknesses smaller than a given threshold thickness $\delta_{c}$ :

$$
T_{B f}\left(\theta, p, f, U_{10}\right)=\int_{\delta_{c}}^{\infty} F\left(U_{10}, \bar{\delta}\right) \cdot T_{s} \cdot e_{B f}(\theta, p, f, \bar{\delta}) d \bar{\delta}
$$

[68] The prediction of the model applied at L-band (hereafter denoted L-Model) considering that all breaking surface waves $\left(\delta_{c}=0\right)$ contribute to the emissivity change or that only breaking waves longer than $15 \mathrm{~m}\left(\delta_{c} \sim 0.5 \mathrm{~m}\right)$ or longer than $35 \mathrm{~m}\left(\delta_{c} \sim 1.2 \mathrm{~m}\right)$ will contribute is compared to the SMOS GMF in Figure 12. As illustrated, the model predictions tend toward the observations when considering that only breaking surface waves longer than $35 \mathrm{~m}$ will generate sufficiently thick layers of foam to be detected by the L-band radiometer. In these conditions, the predicted rate of growth of the emissivity is close to the bi-linear trend observed in the GMF. This supports the idea that the emissivity growth is dominated by the increase in active breaking density of the longest surface wave scales.

[69] In the case of Igor, the NCEP/NAH wave model data reveal (not shown here) that the wavelength at the peak of the ocean gravity wave spectrum evolved from $\sim 120 \mathrm{~m}$ on the 11th Sep to $300-400 \mathrm{~m}$ from the 12th to the 22 Sep. 


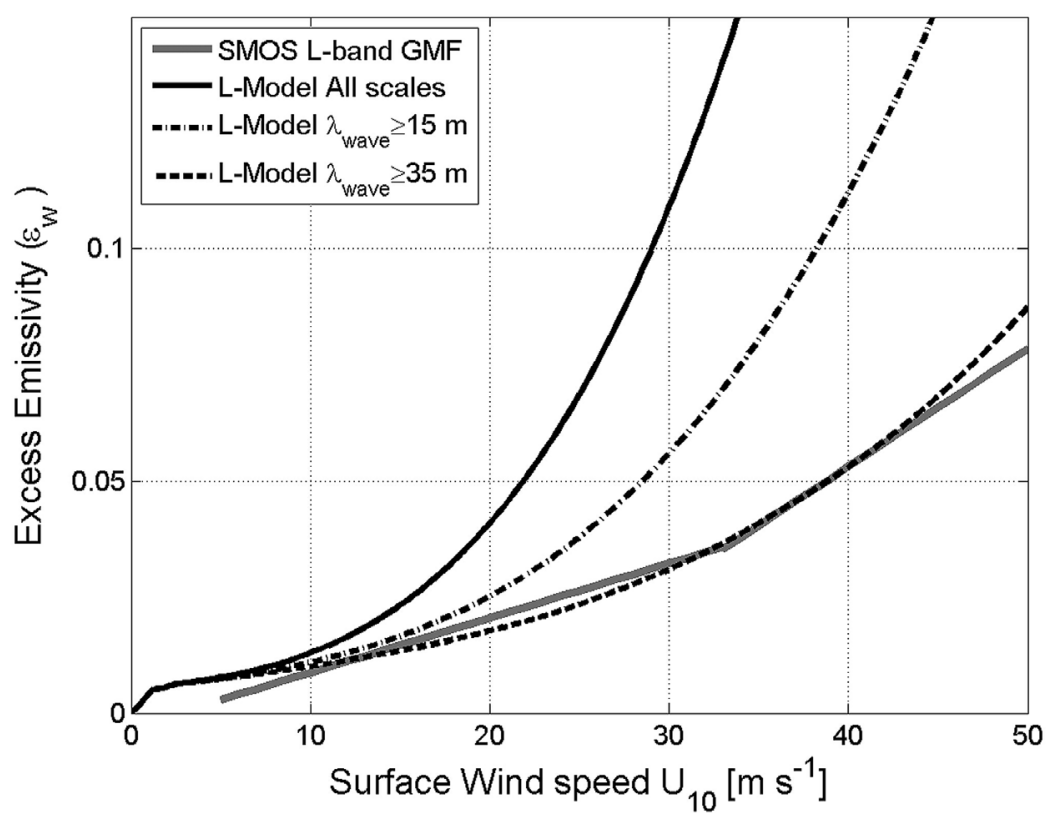

Figure 12. SMOS L-band GMF of the wind excess emissivity (thick gray) and foam emissivity model predictions at L-band for different cut-off wavelengths: all surface wave scales considered in the model (thick black), only waves longer than $15 \mathrm{~m}$ (dash-dotted black) or $35 \mathrm{~m}$ (dotted black) are considered in the model.

During the 17th and 19th SMOS overpasses of Igor, which were used to build up the SMOS GMF, the maximum significant wave height ranged from 10 to $18 \mathrm{~m}$. It can be expected that the very long and very high dominant surface waves encountered in these conditions were continuously breaking (see Figure 1). According to our forward model, the L-band SMOS sensor would have only detected foam formation generated by breaking waves with lengths ranging from the peak wavelength of the spectrum $\lambda \mathrm{p}$ to $\sim \lambda \mathrm{p} / 10$.

[70] A characteristic feature of the SMOS retrieved winds with respect $\mathrm{H}^{*} \mathrm{WIND}$ is an higher asymmetry around the Hurricane eyes, particularly as the Hurricane weakened (e.g., Figures 7 and $8 \mathrm{f}-8 \mathrm{~h}$ ). Since surface winds and wave distribution are by construction, non symmetrically distributed in the different storm quadrants around the hurricane eye centers, so will be the largest breaking waves (wavelengths scale $>\mathrm{O}(10-100)$ meters), and hence, the L-band radiobrightness contrast seen in SMOS data. Hurricane wind fields are characteristically intense, spatially inhomogeneous and directionally varying. As the generation source, the hurricane wind field is central to an understanding of the resultant wavefield and related SMOS $\Delta \mathrm{T}_{\mathrm{B}}$. The large gradients in wind speed and the rapidly varying wind directions of the hurricane vortex generate extremely complex ocean wavefields. The wind field is typically asymmetric, with higher winds to the right (northern hemisphere) of the hurricane center. The wavefield has an even greater degree of asymmetry due to the combined influence of the asymmetry of the wind field and the extended fetch which exists within a translating hurricane. The wind vector in the intense wind region to the right of the storm center (northern hemisphere) is approximately aligned with the direction of forward propagation. Hence, waves generated in this region tend to move forward with the hurricane and therefore remain in high wind regions for an extended period of time. In contrast, waves generated on the low wind side of the storm (left side in northern hemisphere) propagate in the opposite direction to the hurricane translation and rapidly move away from the high wind areas. As found at C-band with the SFMR, it appears that the sea state has also an influence on the retrieved wind speeds from L-band radiometer in hurricanes. This is in the significant differences in SMOS$\mathrm{H}^{*} \mathrm{WIND} / \mathrm{GFDL}$ wind biases among storm quadrants, suggesting the possibility of a $T_{B}$ dependence on fetch.

\section{2. $\mathbf{T}_{B}$ Dependence on Rain Rate}

[71] While much less sensitive to rain than at the higher microwave frequencies, the L-band radiation may still be affected in the hurricane rainbands, in particular in the presence of very strong rain rates. Potentially, the SMOS reported enhancement in the emissivity sensitivity to wind speed above hurricane force, that we previously attributed to sea state changes, could be also associated to the more frequent impact of heavy rain events at the highest winds. Whether a forecaster or scientist can get away with neglecting rainfall at L-band is an important question to investigate. Equation (2) shows that the rain impact shall be about a factor 2 higher at $60^{\circ}$ incidence angle than at $10^{\circ}$. As reported in Figure 5a, $\mathrm{T}_{\mathrm{B}}$ data acquired over the full incidence angle range however all appear to behave similarly above the hurricane wind speed threshold, likely indicating a weak effect of rain on average.

[72] In an attempt to further partially answer this question, we analyzed the SFMR data acquired concomitantly with SMOS data for the 19th evening overpass of Igor. As illustrated in Figure 13, an Air Force C-130 aircraft flight 


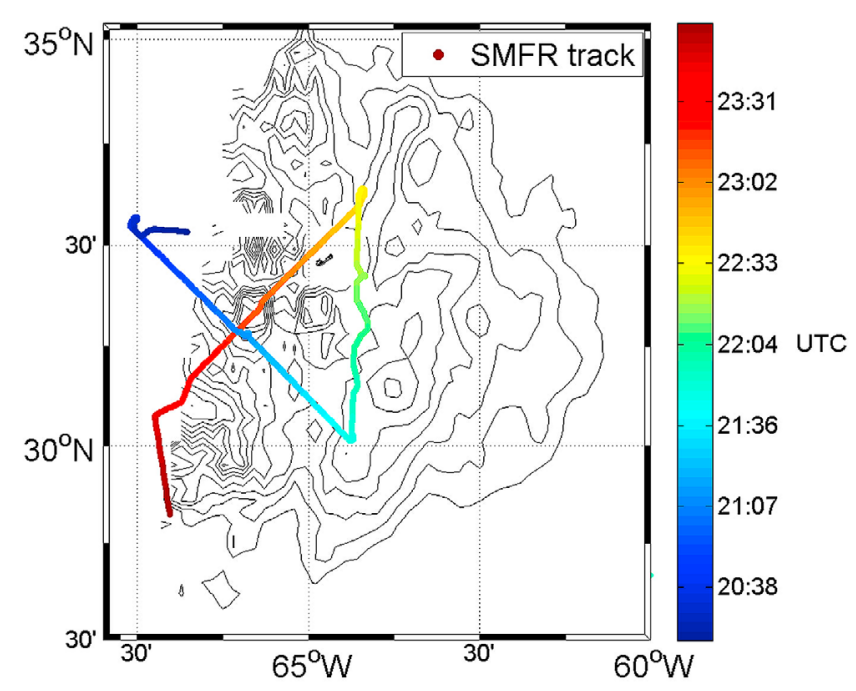

Figure 13. Contours of SMOS retrieved wind speed (black) for the 19 Sep evening overpass of Igor at 2219 UTC. Contours are ranging from 15 to $40 \mathrm{~m} \mathrm{~s}^{-1}$ with a $2.5 \mathrm{~m} \mathrm{~s}^{-1}$ step. The colored track of the Air Force C-130 aircraft flight equipped with an SMFR instrument is superimposed. The color code is indicating the UTC time evolution during the aircraft flight. was conducted over Igor with SFMR data acquired within $\pm 1 \mathrm{~h}$ from SMOS acquisition performed at 2219 UTC. The SFMR retrieved wind speeds and rain rates together with the SMOS retrieved wind speeds interpolated along the aircraft track are shown in Figure 14a. As illustrated, the SMOS retrieved winds along the track are in good agreement with the SFMR ones. Around 2100 UTC, the aircraft flew across a rainband with a rain rate greater than $30 \mathrm{~mm} \mathrm{~h}^{-1}$, located northwest of the eyewall. SSM/I F17 and $\mathrm{F} 16$ retrieved rain rates for satellite overpasses at 2148 UTC and 2256 UTC, respectively, both indicate that this rainband probably persisted at the time of SMOS acquisition, with an estimated rain rate of $\sim 15 \mathrm{~mm} \mathrm{~h}^{-1}$ as observed at a spatial resolution of $\sim 40 \mathrm{~km}$. Another rainband with rain rates higher than $\sim 10 \mathrm{~mm} \mathrm{~h}^{-1}$ was also consistently detected in SSM/I F16 and F17 data, located southwest of the eyewall. Apparently, this additional rainband was not probed by the $1 \mathrm{~km}$ resolution SFMR sensor when the aircraft overpassed it at $\sim 23$ UTC. No significant SMOS wind biases are observed in these two rainbands. Keeping in mind that the northwest rainband overflight for SMOS and SFMR sensors were $\sim 1 \mathrm{~h}$ apart and that their spatial resolution significantly differs, the C-band SFMR $\mathrm{T}_{\mathrm{B}}$ are shown in Figure 14b as function of the co-registered SMOS L-band brightness temperatures and the SFMR retrieved rain rates. As illustrated, the C-band $T_{B}$ strongly

(a)

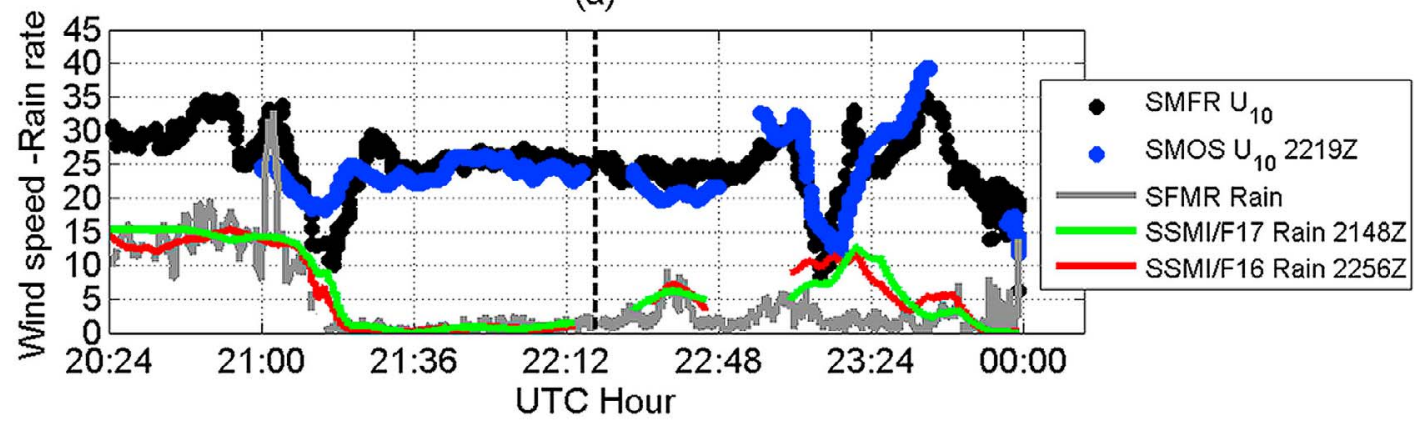

(b)

$\mathrm{mm} / \mathrm{h}$

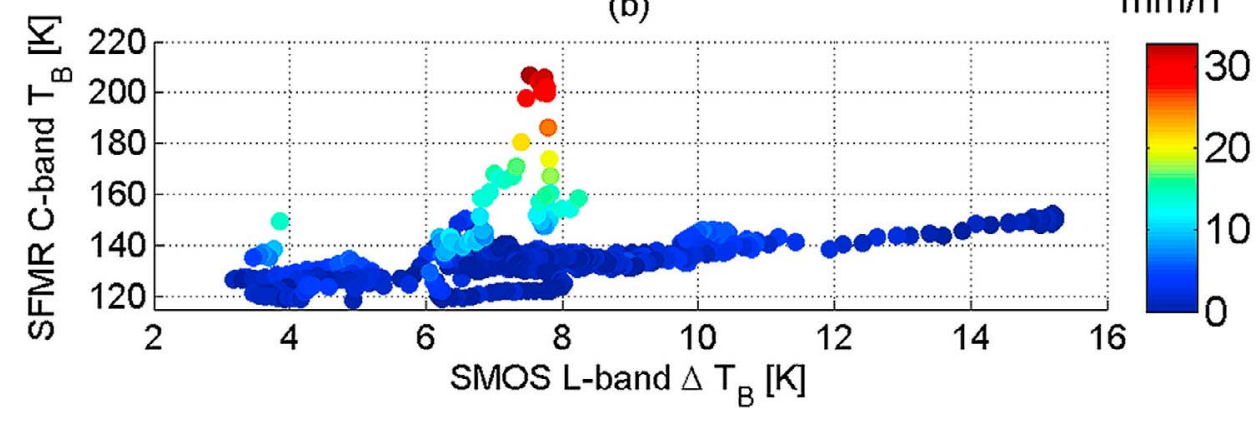

Figure 14. (a) SFMR retrieved surface wind speed (black) in $\mathrm{m} \mathrm{s}^{-1}$ and rain rate (gray) in $\mathrm{mm} \mathrm{h}^{-1}$ as function of time along the Air Force C-130 aircraft flight track for the 19th Sep. The SMOS retrieved wind speed interpolated along the aircraft track is given in blue. Vertical dashed line is indicating time of SMOS overpass of Igor at 2219 UTC. Rain Rates interpolated along the aircraft track from SSMI/F17 at 2148 UTC (green) and F16 at 2256 UTC (red) are also shown. (b) SFMR C-band $T_{B}$ at flight level as function of the SMOS L-band $\Delta \mathrm{T}_{\mathrm{B}}$ interpolated along the aircraft track. The color is indicating the SFMR retrieved rain rate $\left[\mathrm{mm} \mathrm{h}^{-1}\right]$. 
departs from the expected wind-excess linear relationship between C-band and L-band brightness temperatures, as soon as the rain rate exceed $10 \mathrm{~mm} \mathrm{~h}^{-1}$. Because of the acquisition time difference, the strong intermittence of rain events in tropical cyclone rainbands and the varying beamfilling effect between both sensors, the differing impact of rain on $\mathrm{T}_{\mathrm{B}}$ between L-band and C-band cannot be firmly established based on that analysis. Nevertheless, these results tend to indicate a significantly smaller effect of rain at $\mathrm{L}$-band than at $\mathrm{C}$-band.

[73] The effect of rain on the L-band brightness temperature at high winds could be as well tentatively further studied considering the SMOS overpasses of Igor for which rain rate estimates from other spaceborne sensors were acquired close in time from SMOS acquisitions. As illustrated in Figure 15, four SMOS overpasses of Igor out of nine could be coregistered with rain rate observations acquired less than half an hour apart from the SMOS ones. Thus, as Igor was intercepted by SMOS the 11th at 2051Z, it was also imaged by TRMM/TMI at 2054Z. The 13th September, both SMOS and WindSat sensors partly imaged the hurricane at $2116 \mathrm{Z}$. As well, SSMIS/F17 intercepted the hurricane the 15th and the 19th September, with a time lag less than half an hour from SMOS morning overpasses. The rain rate estimates from these sensors, originally derived at $25 \mathrm{~km}$ resolution, were interpolated on the SMOS grid (nearest-neighbor) and are generally higher than $10 \mathrm{~mm} / \mathrm{h}$ in the eyewall regions where they reach maximum values ranging from $\sim 14$ to $17 \mathrm{~mm} / \mathrm{h}$. Several distant rainbands are also observed spiraling around the eyes with encountered rain rates varying from 3 to $17 \mathrm{~mm} / \mathrm{h}$ (reached at $\left[39.5^{\circ} \mathrm{W} ; 21.5^{\circ} \mathrm{N}\right]$ the 11 th). For the two cases in Figure $15 \mathrm{c}$ to $15 \mathrm{f}$, the highest rain rates region are found at the same locations than the brighter ones. However, this is not systematically observed for the two other cases (Figures 15a, 15b, 15g, and 15h). For the latter overpasses, no particular enhancement of the brightness temperatures can be visually detected in the figures where the highest rain rates occurred.

[74] Despite the fact that the rain rates may dramatically evolve within rainbands over time scale on the order of $20 \mathrm{~min}$, an attempt to quantitatively evaluate the rain impact at a given wind speed was performed collecting the ensemble data set for these four overpasses. To this aim, the data from each case were first re-gridded on an eye-centered coordinate system to account for the TC motion in between SMOS and the other sensor acquisition times and further averaged at $25^{\circ}$ resolution. Among the four studied cases, Hwind analyses were only available for the 19th morning overpass so that we choose to use GFDL model products to consistently characterize the surface wind speed for all cases. In Figure 16a, we show the brightness temperature evolution as function of the surface wind speed and of the co-registered rain rates. Although there is no clear stratification observed in the brightness temperatures as function of increasing rain rate for fixed wind speed values, apparently, higher brightness temperatures are in general measured by SMOS in presence of rain than in rain-free conditions. The median brightness temperature values over $1 \mathrm{~m} / \mathrm{s}$ wind speed bins were estimated in rain-free and rainy conditions and are shown in Figure 16b. For wind speed values below $\sim 30 \mathrm{~m} / \mathrm{s}$, the median Tbs are found slightly higher in rainy conditions than without rain. The corresponding median rain rate values within each wind speed bin are shown to increase from $\sim 4 \mathrm{~mm} / \mathrm{h}$ at $\sim 15 \mathrm{~m} / \mathrm{s}$ to about $14 \mathrm{~mm} / \mathrm{h}$ as the wind speed reaches $\sim 30 \mathrm{~m} / \mathrm{s}$. For wind speed below $\sim 30 \mathrm{~m} / \mathrm{s}$, the SMOS GMF function established previously is consistent with observations in rain-free conditions alone, which indicates a weak average impact of the rain when deriving our model.

[75] For wind speed below $30 \mathrm{~m} / \mathrm{s}$, the differences in brightness temperature between rainy and rain-free conditions have a mean value of $\sim 1 \mathrm{~K}$ with a standard deviation of $\sim 0.5 \mathrm{~K}$. They are always found smaller than $1.6 \mathrm{~K}$ and they do not exhibit a clear trend as function of increasing rain rate. According to the SMOS GMF sensitivity to wind speed in that range $\left(\sim 0.35 \mathrm{~K} / \mathrm{m} \mathrm{s}^{-1}\right)$, neglecting the rain impact up to rain rate of $\sim 15 \mathrm{~mm} / \mathrm{h}$ for wind speed below $30 \mathrm{~m} / \mathrm{s}$ shall therefore translate into maximum wind speed error below $5 \mathrm{~m} / \mathrm{s}$.

[76] Unfortunately, most of the brightness temperature data collected above hurricane force are associated with rainy conditions and the contributions to wind and raininduced emission cannot be separated. Based on radiative transfer model and some scaling assumptions, we previously estimated that the maximum TB changes induced by rain could reach $4 \mathrm{~K}$ in very intense precipitation. If one assumes that the GMF function that we found above hurricane force is not affected by rain impact on the mean (as found at lower wind speeds), then neglecting rain effect would translate into a maximum rain-induced wind speed bias of $\sim 5 \mathrm{~m} / \mathrm{s}$. In opposition, if one assume that the step change observed in the GMF sensitivity to wind speed from $0.35 \mathrm{~K} / \mathrm{m} \mathrm{s}^{-1}$ below hurricane force, to $0.75 \mathrm{~K} / \mathrm{m} \mathrm{s}^{-1}$ above it is purely induced by rain contributions, than, neglecting the rain effect shall translate into maximum rain-induced wind speed biases on the order of $\sim 10 \mathrm{~m} / \mathrm{s}$.

[77] Given these few example acquired over Igor, it is yet difficult to firmly conclude on the potential rain effect at L-band above Hurricane force. A more important data set of co-registered brightness temperature and rain rate data will be required from an ensemble of TCs to established reliable statistics in these conditions.

\section{Summary}

[78] A review of the expected signature of L-band radiobrightness contrasts in hurricanes have been first provided in this paper. As shown, the sensitivity of the ocean L-band brightness temperature to wind speed is on the order of $0.3 \mathrm{~K}$ $\mathrm{m} \mathrm{s}^{-1}$ for wind speed below $\sim 25 \mathrm{~m} \mathrm{~s}^{-1}$; it is weakly dependent on the incidence angle over the range $20^{\circ}-50^{\circ}$, and neglecting the wind direction dependencies shall yield maximum $0.3 \mathrm{~K}$ amplitude errors in these conditions. On one hand, available geophysical model functions for the wind excess emissivity at L-band and high winds [Yueh et al., 2010], on which these estimates were based, are however limited to wind speeds smaller than $\sim 25 \mathrm{~m} \mathrm{~s}^{-1}$. On the other hand, currently developed physical models [Reul and Chapron, 2002, 2003] for the foam-induced emissivity at L-band as function of surface wind seem to significantly overestimate the observed contributions: a new analysis of the wind-induced dependencies at L-band and high wind was therefore desired. 

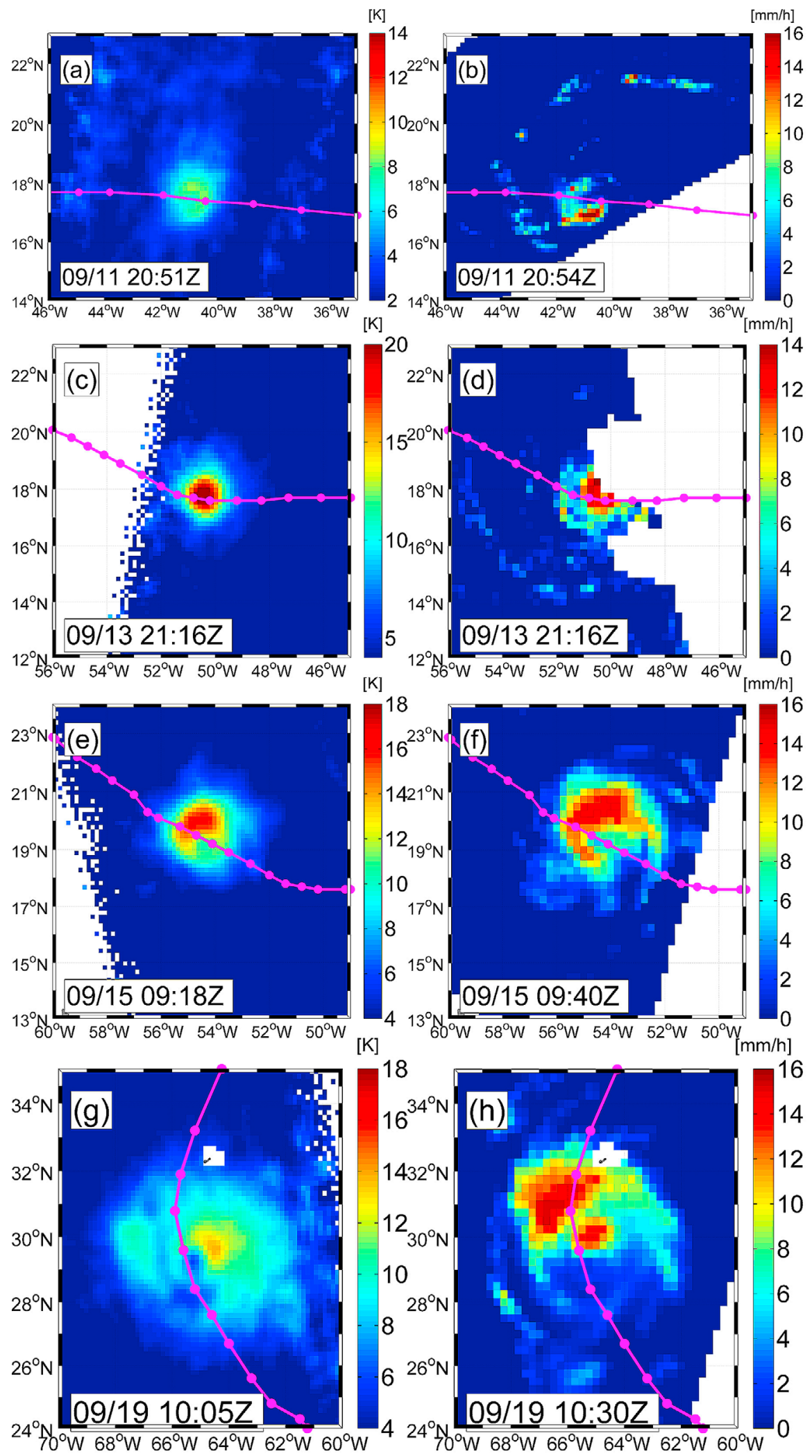

Figure 15. SMOS passes over Igor for which rain rate estimates are available from other spaceborne sensors at an acquisition time less than half an hour from SMOS ones. (left) SMOS wind-excess First Stokes Brightness Temperature parameter $\Delta\left(T_{h}+T_{v}\right) / 2$ in Kelvins. (a) 20:54 Z 11 Sep, (c) 21:16 Z $13 \mathrm{Sep}$, (e) 09:18 Z $15 \mathrm{Sep}$, (g) 10:05 Z $19 \mathrm{Sep}$. (right) Rain rate estimates in mm/h from (b) TRMM/ TMI 20:51 Z 11 Sep, (d) WindSat 21:16Z 13 Sep, and from SSMIS/F17: (f) 09:40Z 15 Sep and (h) 10:30 Z 19 Sep. The magenta dotted curve indicates the ATCF best-track. 
(a)

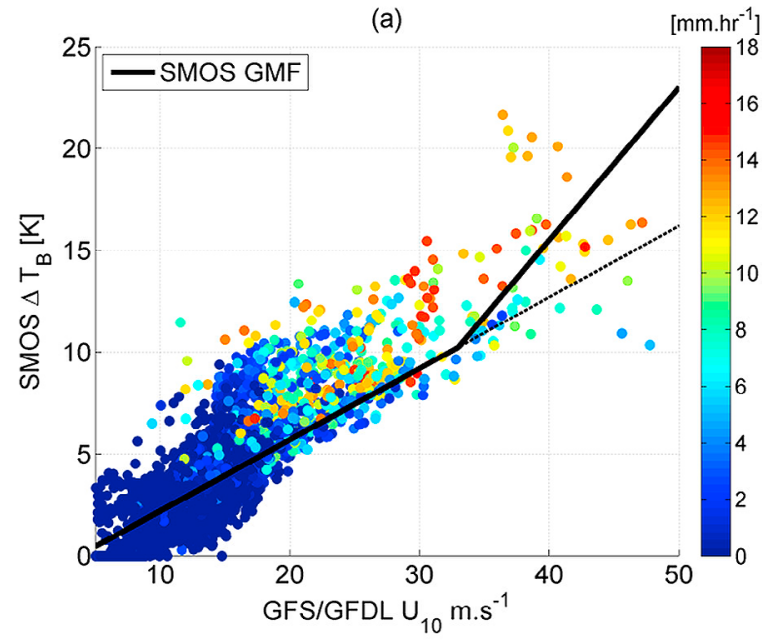

(b)

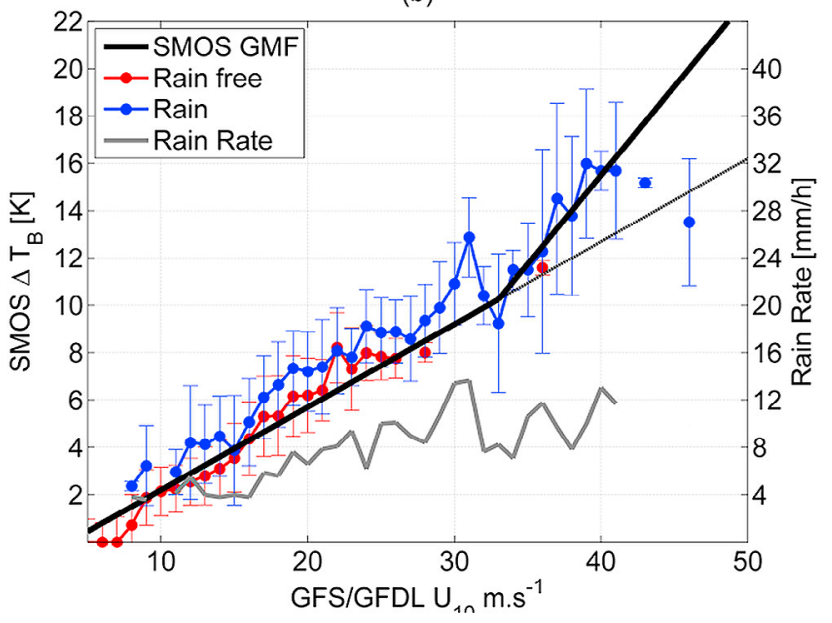

Figure 16. (a) SMOS wind-excess First Stokes Brightness Temperature parameter $\Delta(\mathrm{Th}+\mathrm{Tv}) / 2$ in Kelvins as function of GFS/GFDL surface wind speed in $\mathrm{m} / \mathrm{s}$ ( $x$ axis) and rain rates in $\mathrm{mm} /$ hour (color) for all the passes shown in Figure 15. (b) Bin-averaged brightness temperature as function of the GFDL surface wind speed for rain-free free conditions (red curve) and in presence of rain rates (blue curve). The vertical bars indicate \pm 1 standard deviation within each wind speed bin. The gray curve shows the median rain rate value in each wind speed bin. In both Figure 16a and Figure 16b the black lines indicate the SMOS GMF as expressed in equation (3).

[79] Neglecting the contributions of rain and spray to the L-band brightness temperature observed over the ocean at high winds shall be negligible in general, except in very high rain rates for which maximum rain impact can reach $\sim 4 \mathrm{~K}$ according to radiative transfer simulations. Atmospheric contributions dominated by absorption and emission due to oxygen at L-band can be corrected with negligible errors with respect the expected magnitude of the wind-induced surface radio-brightness contrasts.

[80] While significantly less sensitive than the higher microwave frequencies, spaceborne L-band radiometer observations over the ocean are therefore likely dominated by the varying impact of sea foam generated by breaking waves, which mainly depends on surface wind strength and sea state development. New SMOS measurements at $1.4 \mathrm{GHz}$ offer a unique opportunity to complement existing high wind observations that are often contaminated by heavy rain and clouds. To illustrate this new capability, we analyzed SMOS data during the evolution of the hurricane Igor in the North Atlantic, that developed from a tropical storm to a Saffir-Simpson category 4 hurricane, from September 2010, 11 th to 19 th. The L-band wind-induced excess brightness temperatures $\left(\mathrm{T}_{\mathrm{B}}\right)$ appear weakly incidence-angle dependent in extreme weather conditions and is certainly less sensitive to roughness and foam changes than at the higher C-band microwave frequencies. On average, $T_{B}$ at resolution of $\sim 50 \mathrm{~km}$ is nevertheless increasing quasi-linearly with the surface wind speed. As also found at C-band in the SFMR data, the SMOS L-band brightness temperature contrasts behave differently below and above the Hurricane-force wind speed threshold $\left(\sim 33 \mathrm{~m} \mathrm{~s}^{-1}\right)$, exhibiting a higher sensitivity above that threshold. Based on this empirical relationship, two-dimensional surface wind speed fields were retrieved from SMOS data. SMOS estimated extreme surface wind speeds correlate very well with the major surface wind speed features. In particular, retrieved estimates of the radii of $34,50,64$ knots and of maximum winds are found very consistent with hurricane model outputs, NHC best-track data and $\mathrm{H}^{*}$ Wind observation analysis. In addition, SMOS retrieved maximum 10-min winds at a resolution of $50 \mathrm{~km}$ exhibit a coherent temporal evolution as it overpassed Igor, reaching a maximum intensity of $41 \mathrm{~m} \mathrm{~s}^{-1}$ when the NHC maximum sustained winds reached $\sim 60 \mathrm{~m} \mathrm{~s}^{-1}$. Clearly, the SMOS products were demonstrated to bring added-value information over Igor with respect to METOP/ASCAT or ECMWF model.

[81] However, local discrepancies between the new L-band wind products and the other model or observation-based wind products were detected, with SMOS data exhibiting higher wind speed asymmetries around the eye centers, particularly as the hurricane intensity damped but the sea state remained high. A re-analysis of the emissivity model tend to support the idea that only large actively breaking waves, longer than $\sim 30 \mathrm{~m}$ are contributing to the L-band windexcess emissivity signal at High winds. Given the complex distribution of the large-scale waves around the hurricane eye, a fetch-dependence in the $T_{B} S$ not accounted for might explain the local discrepancies in the retrieved winds.

[82] Attempts to assess the potential impact of heavy rain on the brightness temperature at L-band were done based on co-registered brightness temperatures, wind speeds and rain rates data. While clearly less sensitive to rain than at higher frequencies, it is likely that the surface wind speed retrieved from L-band radiometer data will be also biased in very heavy rain conditions. We indeed concluded that neglecting the rain impact up to rain rate of $\sim 15 \mathrm{~mm} / \mathrm{h}$ for wind speed below $30 \mathrm{~m} / \mathrm{s}$ shall translate into maximum wind speed error below $5 \mathrm{~m} / \mathrm{s}$. From our analysis, we also estimated that the maximum rain impact of $4 \mathrm{~K}$ potentially encountered in the eyewall highest wind and highest precipitation area 
( $\sim 90 \mathrm{~mm} / \mathrm{h}$ rain rates) might translate into a wind speed bias varying from $\sim 5$ to $10 \mathrm{~m} / \mathrm{s}$. It is however difficult to firmly conclude on the potential very heavy rain effect above hurricane force as very little rain free observations were found in these conditions during Igor. A more important data set of co-registered brightness temperature, wind speed and rain rate data will be required from an ensemble of TCs to established reliable statistics in these conditions. The use of the multiangular capacity of SMOS to flag and/or correct residual rain impact can be also anticipated.

[83] Major limitations currently identified in the SMOS retrieved surface winds are certainly also related to the relatively low spatial-resolution of the instrument $(\sim 50 \mathrm{~km})$ and to the increased noise level when the Hurricane is imaged on the border of the swath.

[84] Nevertheless, we believe that the SMOS inferred high wind products will clearly provide quantitative complementary surface wind information of interest for operational Hurricane intensity forecast models.

[85] Acknowledgments. The authors would like to thank both reviewers for useful comments and suggestions. In particular we acknowledge Brad Klotz (Rosenstiel School of Marine and Atmospheric Science, Miami) and Eric Uhlhorn from NOAA/AOML/Hurricane Research Division for providing us with some of the data sets used in this study and for useful discussions. This work was partly done under ESA contract ESA ESRIN/RFQ/3-12269/08/I-LGSMOS and partly financed by CNES in the context of development of the Expert Support Laboratory of the Centre Aval de Traitement des Données SMOS (CATDS).

\section{References}

Allen, W. T. R. (1983), Wind and Sea: State of Sea Photographs for the Beaufort Wind Scale, 57 pp., Atmos. Environ. Serv., Environ. Can., Ottawa.

Anguelova, M. D. (2008), Complex dielectric constant of sea foam at microwave frequencies, J. Geophys. Res., 113, C08001, doi:10.1029/ 2007JC004212.

Anterrieu, E., P. Waldteufel, and A. Lannes (2002), Apodization functions for 2-D hexagonally sampled synthetic aperture imaging radiometers, IEEE Trans. Geosci. Remote Sens., 40(12), 2531-2542, doi:10.1109/ TGRS.2002.1176146.

Ardhuin, F., B. Chapron, and F. Collard (2009), Observation of swell dissipation across oceans, Geophys. Res. Lett., 36, L06607, doi:10.1029/ 2008GL037030.

Bettenhausen, M. H., C. K. Smith, R. M. Bevilacqua, N.-Y. Wang, P. W. Gaiser, and S. K. Cox (2006), A nonlinear optimization algorithm for WindSat wind vector retrievals, IEEE Trans. Geosci. Remote Sens., 44(3), 597-610, doi:10.1109/TGRS.2005.862504.

Black, P. G., R. W. Burpee, N. M. Dorst, and W. L. Adams (1986), Appearance of the sea surface in tropical cyclones, Weather Forecast., 1 , 102-107, doi:10.1175/1520-0434(1986)001<0102:AOTSSI>2.0.CO;2.

Bondur, V. G., and E. A. Sharkov (1982), Statistical properties of whitecaps on a rough sea, Oceanology, Engl. Transl., 22, 274-279.

Boutin J., et al. (2011), Sea surface salinity as measured by SMOS and by surface autonomous drifters, paper presented at General Assembly, Eur. Geosci. Union, Vienna, 3-8 April.

Boyer, T. P., J. I. Antonov, H. E. Garcia, D. R. Johnson, R. A. Locarnini, A. V. Mishonov, M. T. Pitcher, O. K. Baranova, and I. V. Smolyar (2006), World Ocean Database 2005 [DVDs], NOAA Atlas NESDIS, vol. 60, edited by S. Levitus, 190 pp, U.S. Govt. Print. Off., Washington, D. C.

Camps, A., et al. (2005), The emissivity of foam-covered water surface at L-band: Theoretical modeling and experimental results from the FROG 2003 field experiment, IEEE Trans. Geosci. Remote Sens., 43, 925-937, doi:10.1109/TGRS.2004.839651.

Chao, Y. Y., and H. L. Tolman (2001), Specification of hurricane wind fields for ocean wave prediction, in Ocean Wave Measurement and Analysis, edited by B. L. Edge and J. M. Hemsley, pp. 671-679, Am. Soc. of Civ. Eng., San Francisco, Calif.

Chao, Y., L. Burroughs, and H. Tolman (2003), Wave forecasting for the western North Atlantic and adjacent waters, Tech. Proced. Bull. 495, Natl. Weather Serv., NOAA, U.S. Dep. of Commer., Washington, D. C. [Available at http://polar.ncep.noaa.gov/mmab/tpbs/operational.tpbs/ tpb495/tpb495.htm.]
Chen, S. S., W. Zhao, M. A. Donelan, J. F. Price, and E. J. Walsh (2007), The CBLAST-Hurricane program and the next-generation fully coupled atmosphere-wave-ocean models for hurricane research and prediction, Bull. Am. Meteorol. Soc., 88, 311-317, doi:10.1175/BAMS-88-3-311.

Collard, F., F. Ardhuin, and B. Chapron (2009), Monitoring and analysis of ocean swell fields from space: New methods for routine observations, J. Geophys. Res., 114, C07023, doi:10.1029/2008JC005215.

Delpey, M. T., F. Ardhuin, F. Collard, and B. Chapron (2010), Space-time structure of long ocean swell fields, J. Geophys. Res., 115, C12037, doi:10.1029/2009JC005885.

Donelan, M. A., B. K. Haus, N. Reul, W. J. Plant, M. Stiassnie, H. C. Graber, O. B. Brown, and E. S. Saltzman (2004), On the limiting aerodynamic roughness of the ocean in very strong winds, Geophys. Res. Lett., 31, L18306, doi:10.1029/2004GL019460.

El-Nimri, S. F., W. Lindwood Jones, E. Uhlhorn, C. Ruf, J. Johnson, and P. Black (2010), An improved C-band ocean surface emissivity model at hurricane-force wind speeds over a wide range of Earth incidence angles, IEEE Geosci. Remote Sens. Lett., 7, 641-645, doi:10.1109/ LGRS.2010.2043814

European Centre for Medium-Range Weather Forecasts (2004), Early medium-range forecasts of tropical cyclones, ECMWF Newsl. 102, pp. 7-14, Reading, U. K.

Font, J., A. Camps, A. Borges, M. Martín-Neira, J. Boutin, N. Reul, Y. H. Kerr, A. Hahne, and S. Mecklenburg (2010), SMOS: The challenging sea surface salinity measurement from space, Proc. IEEE, 98(5), 649-665, doi:10.1109/JPROC.2009.2033096

Houze, R. A., Jr., S. S. Chen, B. F. Smull, W.-C. Lee, and M. M. Bell (2007), Hurricane intensity and eyewall replacement, Science, 315, 1235, doi:10.1126/science.1135650.

Jarosz, E., D. A. Mitchell, D. W. Wang, and W. J. Teague (2007), Bottomup determination of air-sea momentum exchange under a major tropical cyclone, Science, 315, 1707-1709, doi:10.1126/science.1136466.

Johnson, J., and M. Zhang (1999), Theoretical study of the small-slope approximation for the ocean polarimetric thermal emission, IEEE Geosci. Remote Sens., 37, 2305-2316, doi:10.1109/36.789627.

Kerr, Y. H., et al. (2010), The SMOS mission: New tool for monitoring key elements of the global water cycle, Proc. IEEE, 98(5), 666-687, doi:10.1109/JPROC.2010.2043032.

Knaff, J. A., M. DeMaria, D. A. Molenar, C. R. Sampson, and M. G. Seybold (2011), An automated, objective, multi-satellite platform tropical cyclone surface wind analysis, J. Appl. Meteorol. Climatol., 50, 2149-2166, doi:10.1175/2011JAMC2673.1.

Mecklenburg, S., N. Wright, C. Bouzinac, and S. Delwart (2009), Getting down to business-SMOS operations and products, ESA Bull., 137, $25-30$.

Meissner, T., and F. J. Wentz (2009), Wind vector retrievals under rain with passive satellite microwave radiometers, IEEE Trans. Geosci. Remote Sens., 47, 3065-3083, doi:10.1109/TGRS.2009.2027012.

Monahan, E., and I. G. O'Muircheartaigh (1980), Optimal power-law description of oceanic whitecap coverage dependence on wind speed, J. Phys. Oceanogr., 10, 2094-2099, doi:10.1175/1520-0485(1980) 010<2094:OPLDOO >2.0.CO;2.

Nordberg, W., J. Conaway, D. B. Ross, and T. Wilheit (1971), Measurements of microwave emission from a foam-covered, wind-driven sea, J. Atmos. Sci., 28, 429-435, doi:10.1175/1520-0469(1971)028<0429: MOMEFA $>2.0 . \mathrm{CO} ; 2$.

Padmanabhan, S., S. C. Reising, W. E. Asher, L. A. Rose, and P. W. Gaiser (2006), Effects of foam on ocean surface microwave emission inferred from radiometric observations of reproducible breaking waves, IEEE Trans. Geosci. Remote Sens., 44(3), 569-583, doi:10.1109/TGRS. 2006.870234.

Pasch, R. J., and T. B. Kimberlain (2011), Tropical cyclone report Hurricane Igor (AL112010), 8-21 September 2010, Natl. Hurricane Cent., Miami, Fla. [Available at http://www.nhc.noaa.gov/pdf/TCR-AL112010_Igor.pdf.] Powell, M. D., S. H. Houston, L. R. Amat, and N. Morisseau-Leroy (1998) The HRD real-time hurricane wind analysis system, J. Wind Eng. Ind Aerodyn., 77-78, 53-64, doi:10.1016/S0167-6105(98)00131-7.

Powell, M. D., P. J. Vickery, and T. A. Reinhold (2003), Reduced drag coefficient for high wind speeds in tropical cyclones, Nature, 422, 279-283, doi:10.1038/nature01481.

Quilfen, Y., J. Tournadre, and B. Chapron (2006), Altimeter dual-frequency observations of surface winds, waves, and rain rate in tropical cyclone Isabel, J. Geophys. Res., 111, C01004, doi:10.1029/2005JC003068.

Quilfen, Y., C. Prigent, B. Chapron, A. A. Mouche, and N. Houti (2007), The potential of QuikSCAT and WindSat observations for the estimation of sea surface wind vector under severe weather conditions, J. Geophys. Res., 112, C09023, doi:10.1029/2007JC004163. 
Quilfen, Y., B. Chapron, and J. Tournadre (2010), Satellite microwave surface observations in tropical cyclones, Mon. Weather Rev., 138, 421-437, doi:10.1175/2009MWR3040.1.

Quilfen, Y., D. Vandemark, B. Chapron, H. Feng, and J. Sienkiewicz (2011), Estimating gale to hurricane force winds using the satellite altimeter, J. Atmos. Oceanic Technol., 28, 453-458, doi:10.1175/JTECH-D10-05000.1.

Raizer, V. (2007), Macroscopic foam-spray models for ocean microwave radiometry, IEEE Trans. Geosci. Remote Sens., 45(10), 3138-3144, doi:10.1109/TGRS.2007.895981.

Reul, N., and B. Chapron (2002), Foam emissivity modeling at L-band, in Scientific Requirements and Impact of Space Observations of Ocean Salinity for Modelling and Climate Studies, Tech. Rep. 214, pp. 60-98, Nansen Environ. Remote Sens. Cent., Bergen, Norway. [Available at http://esamultimedia.esa.int/docs/Study 14273 FR.pdf.]

Reul, N., and B. Chapron (2003), A model of sea-foam thickness distribution for passive microwave remote sensing applications, J. Geophys. Res., 108(C10), 3321, doi:10.1029/2003JC001887.

Reul, N., H. Branger, and J. P. Giovannangeli (2008), Air flow structure over short breaking waves, Boundary Layer Meteorol., 126(3), 477-505, doi:10.1007/s10546-007-9240-3.

Rosenkranz, P., and D. Staelin (1972), Microwave emissivity of ocean foam and its effect on nadiral radiometric measurements, J. Geophys. Res., 77, 6528-6538, doi:10.1029/JC077i033p06528.

Ross, D. B., and V. Cardone (1974), Observations of oceanic whitecaps and their relation to remote measurements of surface wind speed, J. Geophys. Res., 79, 444-452, doi:10.1029/JC079i003p00444.

Ruf, C. S., C. T. Swift, A. B. Tanner, and D. M. Le Vine (1988), Interferometric synthetic aperture microwave radiometry for the remote sensing of the Earth, IEEE Trans. Geosci. Remote Sens., 26, 597-611, doi:10.1109/36.7685.

Ruf, C. S., A. M. Mims, and C. C. Hennon (2008), The dependence of the microwave emissivity of the ocean on hurricane force wind speed, paper presented at 28th Conference on Hurricanes and Tropical Meteorology, Am. Meteorol. Soc., Orlando, Fla., 28 April to 2 May.

Sampson, R. C., and A. J. Schraeder (2000), The automated tropical cyclone forecasting system, version 3.2, Bull. Am. Meteorol. Soc., 81, 1231-1240, doi:10.1175/1520-0477(2000)081<1231:TATCFS >2.3.CO;2.

Schulz, J. (2002), Impact of rain on sea surface brightness temperature, in Scientific Requirements and Impact of Space Observations of Ocean Salinity for Modelling and Climate Studies, Tech. Rep. 214, pp. 51-59, Nansen Environ. Remote Sens. Cent., Bergen, Norway. [Available at http://esamultimedia.esa.int/docs/Study 14273 FR.pdf.]

Sharkov, A. (2006), Breaking Ocean Waves, $27 \overline{8}$ pp., Springer, Berlin.

Skou, N. (2003), Faraday rotation and L-band oceanographic measurements, Radio Sci., 38(4), 8059, doi:10.1029/2002RS002671.

Skou, N., and D. Hoffman-Bang (2005), L-band radiometers measuring salinity from space: Atmospheric propagation effects, IEEE Trans. Geosci. Remote Sens., 43, 2210-2217, doi:10.1109/TGRS.2005.856115.

Smith, P. M. (1988), The emissivity of sea foam at 19 and $37 \mathrm{gHz}$, IEEE Trans. Geosci. Remote Sens., 26, 541-547, doi:10.1109/36.7679.

Soden, B. J., C. S. Velden, and R. E. Tuleya (2001), The impact of satellite winds on experimental GFDL hurricane model forecasts, Mon. Weather Rev., 129(4), 835-852, doi:10.1175/1520-0493(2001) $129<0835$ :TIOSWO $>2.0 . \mathrm{CO} ; 2$.

Stark, J. D., C. J. Donlon, M. J. Martin, and M. E. McCulloch (2007), OSTIA: An operational, high resolution, real time, global sea surface temperature analysis system, in OCEANS 2007, Marine Challenges: Coastline to Deep Sea, pp. 1-4, Inst. of Electr. and Electron. Eng., New York, doi:10.1109/OCEANSE.2007.4302251.
Stogryn, A. (1972), The emissivity of sea foam at microwave frequencies, J. Geophys. Res., 77, 1658-1666, doi:10.1029/JC077i009p01658.

Swift, C. T. (1990), Passive Microwave Remote Sensing of Ocean Surface Wind Speeds in Surface Waves and Fluxes, edited by G. L. Geernaert and W. L. Plant, Kluwer Acad., Dordecht, Netherlands.

Tenerelli, J. E., and S. S. Chen (2002), Intensity change and eyewall replacement in Hurricane Floyd (1999), paper presented at 25th Annual Conference on Hurricanes and Tropical Meteorology, Am. Meteorol. Soc., San Diego, Calif.

Tenerelli, J. E., and N. Reul (2010), Analysis of SMOS brightness temperatures obtained from March through May, paper presented at Living Planet Symposium, Eur. Space Agency, Bergen, Norway, 28 June to 2 July.

Uhlhorn, E. W., and P. G. Black (2003), Verification of remotely sensed sea surface winds in hurricanes, J. Atmos. Oceanic Technol., 20(1), 99-116, doi:10.1175/1520-0426(2003)020<0099:VORSSS > 2.0.CO;2.

Uhlhorn, E. W., P. G. Black, J. L. Franklin, M. Goodberlet, J. Carswell, and A. S. Goldstein (2007), Hurricane surface wind measurements from an operational stepped frequency microwave radiometer, Mon. Weather Rev., 135, 3070-3085, doi:10.1175/MWR3454.1.

Webster, W. J., T. T. Wilheit, D. B. Ross, and P. Gloersen (1976), Spectral characteristics of the microwave emission from a wind-driven foam covered sea, J. Geophys. Res., 81, 3095-3099, doi:10.1029/JC081i018p03095.

Wentz, F. J. (2005), The effect of clouds and rain on Aquarius salinity retrieval, Tech. Memo. 3031805, Remote Sens. Syst., Santa Rosa, Calif. [Available at http://www.ssmi.com/papers/aquarius/rain_effect_on_salinity. pdf.]

Wentz, F. J., and R. W. Spencer (1998), SSM/I rain retrievals within a unified all-weather ocean algorithm, J. Atmos. Sci., 55(9), 1613-1627, doi:10.1175/1520-0469(1998)055<1613:SIRRWA>2.0.CO;2.

Willoughby, H. E. (2007), Forecasting hurricane intensity and impacts, Science, 315(5816), 1232-1233, doi:10.1126/science.1140041.

Wimmers, A. J., and C. S. Velden (2007), MIMIC: A new approach to visualizing satellite microwave imagery of tropical cyclones, Bull. Am. Meteorol. Soc., 88, 1187-1196, doi:10.1175/BAMS-88-8-1187.

Yueh, S. H. (2008), Directional signals in WindSat observations of hurricane ocean winds, IEEE Trans. Geosci. Remote Sens., 46(1), 130-136, doi:10.1109/TGRS.2007.909079.

Yueh, S. H., R. West, W. J. Wislon, F. K. Li, E. G. Njoku, and Y. Rahmatsami (2001), Error sources and feasibility for microwave remote sensing of ocean surface salinity, IEEE Trans. Geosci. Remote Sens., 39, 1049-1060, doi:10.1109/36.921423.

Yueh, S. H., S. J. Dinardo, A. G. Fore, and F. K. Li (2010), Passive and active L-band microwave observations and modeling of ocean surface winds, IEEE Trans. Geosci. Remote Sens., 48(8), 3087-3100, doi:10.1109/TGRS.2010.2045002.

Zine S., J. Boutin, J. Font, N. Reul, P. Waldteufel, C. Gabarró, J. Tenerelli, F. Petitcolin, J.-L. Vergely, and M. Talone (2008), Overview of the SMOS sea surface salinity prototype processor, IEEE Trans. Geosci. Remote Sens., 46(3), 621-645, doi:10.1109/TGRS.2008.915543.

B. Chapron, Y. Quilfen, and N. Reul, Laboratoire d'Océanographie Spatiale, Institut Français de Recherche et d'Exploitation de la Mer, F-29280 Plouzané, France. (nreul@ifremer.fr)

Y. Kerr, Centre d'Etude Spatial de la Biosphère, F-31401 Toulouse CEDEX 09, France.

J. Tenerelli, Radar Division, Collect Localisation Satellite, Avenue La Pérouse Technopôle Brest-Iroise, F-29280 Plouzané, France.

D. Vandemark, Institute for the Study of Earth, Oceans and Space, University of New Hampshire, 8 College Rd., Durham, NH 03824, USA. 